\title{
In-pipe Robot with Active Steering Capability for Moving Inside of Pipelines
}

\author{
Hyouk Ryeol Choi and Se-gon Roh \\ School of Mechanical Engineering, Sungkyunkwan University \\ Korea
}

\section{Introduction}

Pipelines which are tools for transporting oils, gases and other fluids such as chemicals, have been employed as major utilities in a number of countries for long time. Recently, many troubles occur in pipelines, and most of them are caused by aging, corrosion, cracks, and mechanical damages from the third parties. Even though lasting activities for maintenance are strongly demanded, they need enormous budgets that may not be easily handled by related industries. Currently, the applications of robots for the maintenance of the pipeline utilities are considered as one of the most attractive solutions available.

In-pipe robots which have the long history of development in robotics can be classified into several elementary forms according to moving patterns, as shown in Fig. 1, although most of them have been designed depending upon specific applications.

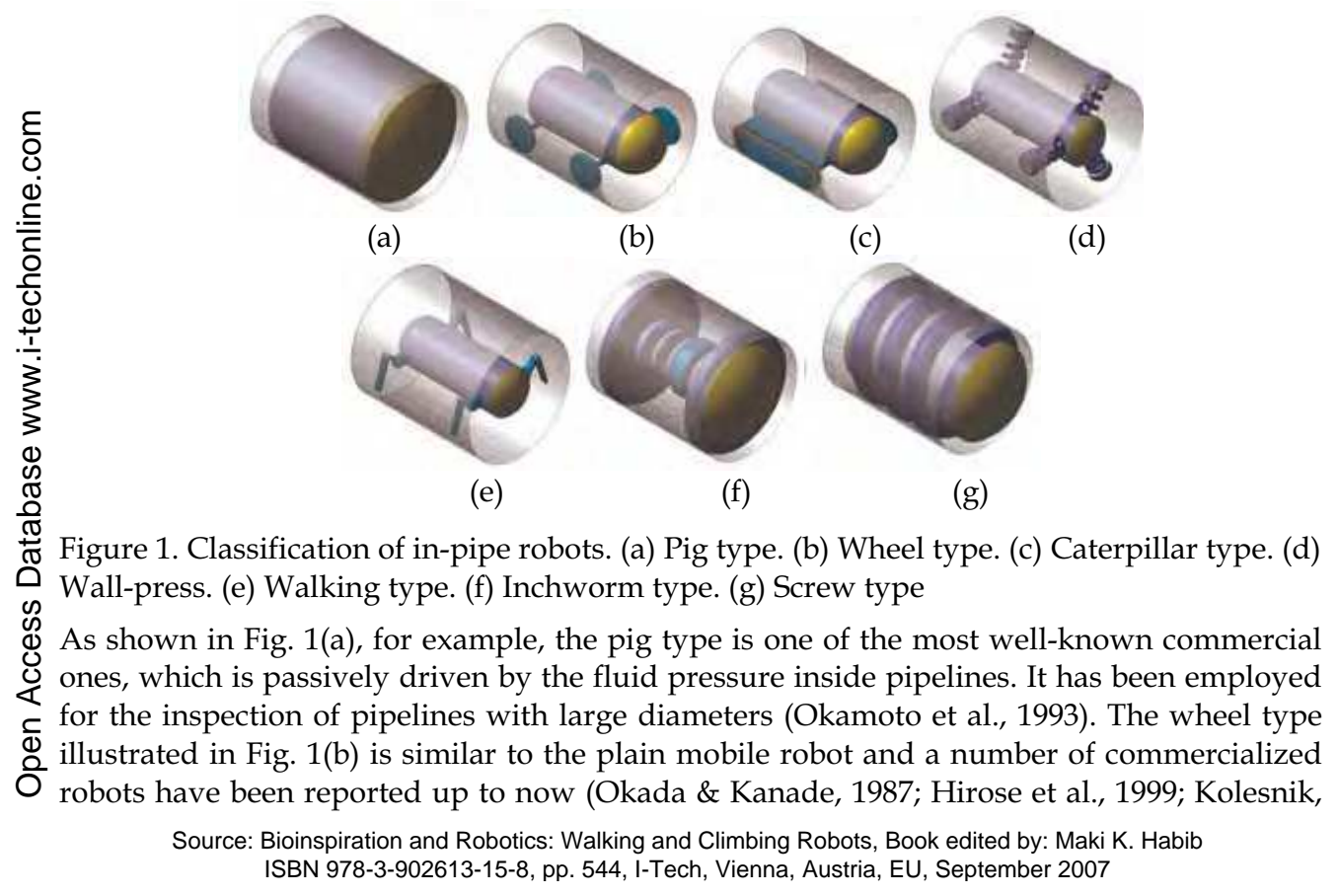


2002; Suzumori et al., 1998; Kawaguchi et al., 1995; Suzumori, et al., 1999; Tsubouchi et al., 2000; Scholl et al., 2000; Mhramatsu et al., 2000; Ong et al., 2001; Choi \& Ryew, 2002; Ryew et al., 2000; Roh et al., 2001; Roh et al., 2002; Roh et al., 2005; Schempf \& Vradis, 2005; Schempf, 2002; Gamble \& Wiesman, 1996). Fig. 1(c) shows the robot with caterpillars instead of wheels (Roman et al., 1993). As shown in Fig. 1(d), the wall press type, which has a number of advantages in climbing vertical pipelines, corresponds to the robot with the flexible mechanism for pressing the wall whatever means they apply with (Ryew et al., 2000; Nagano \& Oka, 1998). As depicted in Fig. 1(e), the walking type possessing articulated legs can produce highly sophisticated motions (Neubauer, 1994; Pfeiffer et al., 2000; Kostin et al., 1993; Nickols et al, 1997). The inchworm type given in Fig. 1(f) is usually employed for pipelines with very small diameters (Fukuda et al., 1989; Kondoh\& Yokota, 1997; Anthierens et al., 2000; Shibata et al., 1998; Tsuruta et al., 2000; Jun et al., 1999; Landsberger \& Martin, 1992; Menciassi et al., 2002; Mitsumoto et al., 2001; Takahashi et al., 1994; Bertetto \& Ruggiu, 2001; Hayashi \& Iwatsuki, 1998; Nishikawa et al., 1999; Anthierens et al., 1999). The screw type (or helical drive type) displays the motion of a screw when it advances in the pipelines as depicted in Fig. 1(g) (Hayashi et al., 1995; Horodinca et al., 2002; Iwashina et al., 1994). Most of in-pipe robots employ the mechanism derived from one of aforementioned basic types of mechanisms or their combinations. In fact, the goals of the in-pipe robot have close relations with the taskspace of specific applications because the principal requirement of the in-pipe robot is that the robot should be able to explore wherever it has to go within its taskspace. Existing robots generally travel along horizontal pipelines successfully, but only part of them can cope with complicated pipeline configurations, such as vertical pipelines, elbows (also called bends, L-shaped pipelines) etc. Furthermore, few of them can negotiate branches (also called T-shaped pipelines). For successful navigation, however, in-pipe robots are strongly demanded to have the ability of negotiating elbows and branches, because urban gas pipelines are configured with a number of special fittings such as elbows, branches and their combinations.

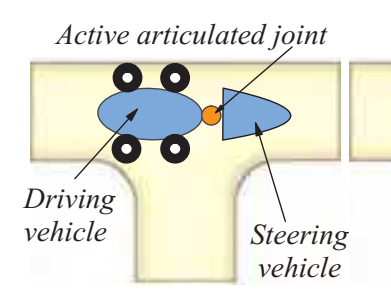

(a)

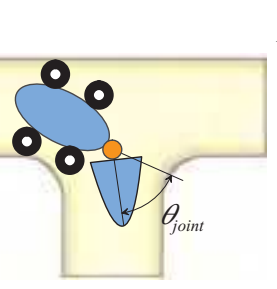

(b)

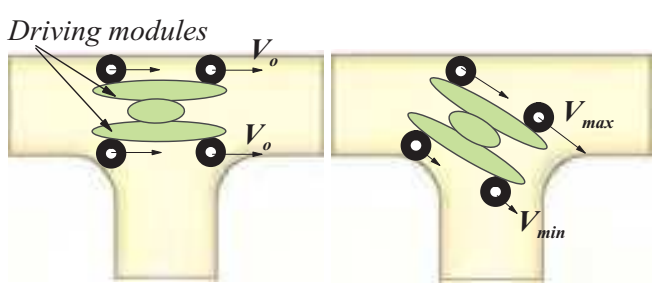

(c)

(d)

Figure 2. Typical methods of steering in branch. (a) Articulated active joint type: straight drive. (b) Articulated active joint type: steering drive. (c) Differential drive type: straight drive. (d) Differential drive type: steering drive

Up to now, several in-pipe robots with steering capability have been reported. They are largely classified into two groups such as an articulated type and a differential-drive one, as shown in Fig. 2. The articulated type is the robot with active articulated joints physically similar to the snake or the annelid animal in nature which may be one of the most adequate mechanism, although its steering mechanism becomes complicated, for example steering joint (Scholl et al., 2000; Schempf \& Vradis, 2005; Gamble \& Wiesman, 1996) rubber gas 
actuated joint (Fukuda et al., 1989) and double active universal joint (Choi \& Ryew, 2002; Ryew et al., 2000). These robots can move along branches. As an alternative approach, the differential drive one that carries out steering by modulating the speeds of driving wheels as shown in Fig. 2 (c) and (d) contains relatively simple mechanisms, whereas modelling and analysis of its movements according to pipelines configurations are prerequisite.

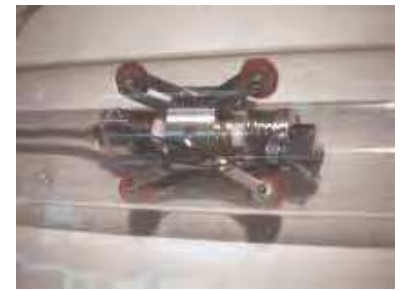

(a)

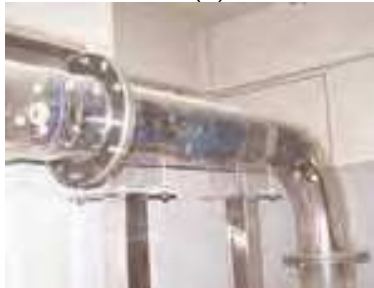

(c)

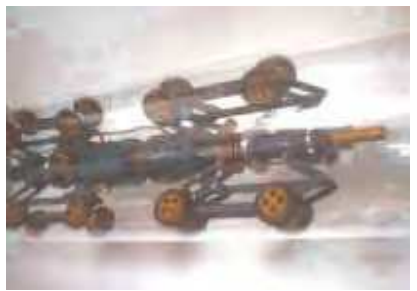

(b)

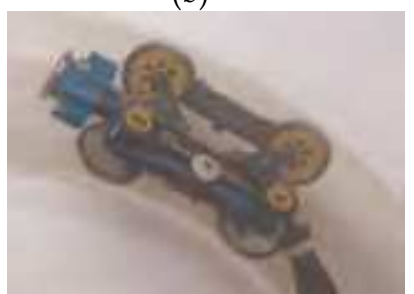

(d)

Figure 3. MRINSPECT Series. (a) MRINSPECT I. (b) MRINSPECT II. (c) MRINSPECT III. (d) MRINSPECT IV

In this chapter, we present a comprehensive work for moving inside pipelines with the inpipe robot, called the Multifunctional Robot for IN-pipe inspection (MRINSPECT) series, as shown in Fig. 3 (Choi \& Ryew, 2002; Ryew et al., 2000; Roh et al., 2001; Roh et al., 2002; Roh et al., 2005). They have been developed for the inspection of urban gas pipelines with a nominal 8-in and 4-in inside diameter, respectively. MRINSPECT III and IV of them can freely move along the basic configuration of pipelines such as horizontal and vertical pipelines. Moreover they can travel along reducers, elbows, and steer in the branches by using steering mechanisms. Especially, their three dimensional steering capability provides outstanding mobility in navigation that is a prerequisite characteristic in pipelines. Even if the robots have steering capability, their steering methods are different from each other. MRINSPECT III is the robot with active articulated joints physically similar to a snake or an annelid animal in nature, which may be one of the most adequate mechanisms. As an alternative approach, MRINSPECT IV is the differential-drive type that carries out steering by modulating the speeds of driving wheels.

This chapter is organized as follows. In Section II, the authors outline technologies in developing in-pipe robots. In Section III, design constraints and critical points of in-pipe robots are introduced. In Section IV, consideration for moving in the fittings such as elbows and branches are discussed, where their geometrical features are described with mathematical expressions. Section V introduces MRINSEPCT series. The issues of mechanism including the driving vehicle and steering mechanism are described in developing MRINSEPCT III and IV. In addition, we briefly introduce MRINSEPCT V which is now under development. Finally we will conclude with summary in Section VI. 


\section{General Configuration of In-pipe Robot}

Generally, In-pipe robot consists of articulated bodies including driving vehicles, control module, tether cable and ground station. The instrumentation module for NDT (NonDestructive Testing) can be attached on the robot optionally.

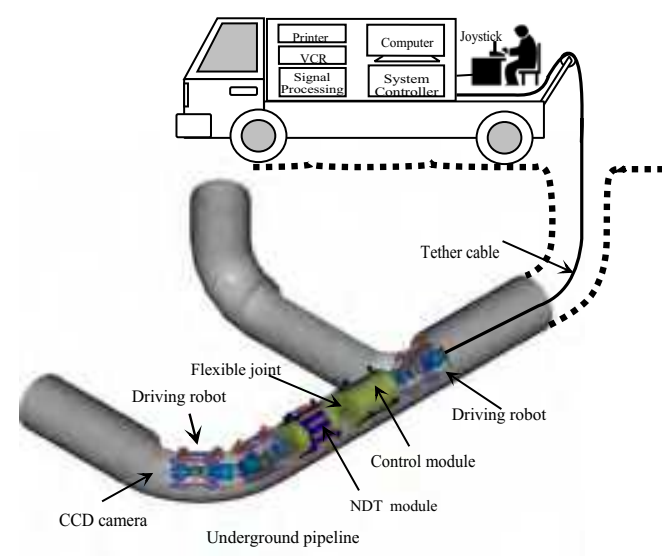

(a)

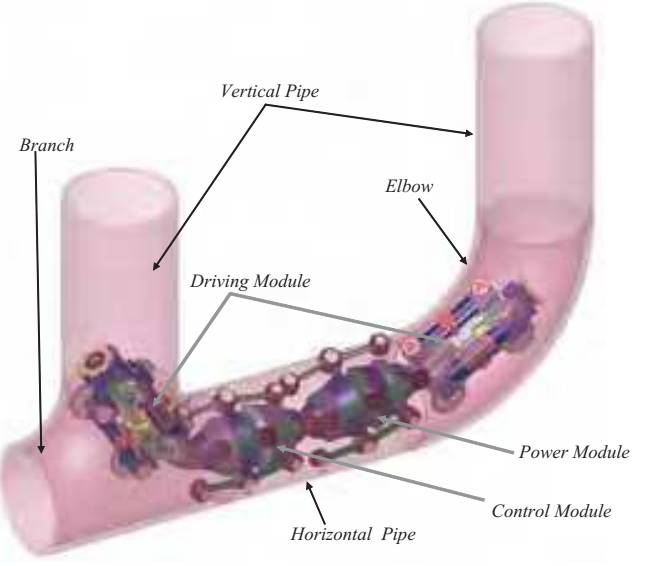

(b)

Figure 4. In-pipe robot system. (a) In-pipe robot system controlled by operator.

(b) Autonomous in-pipe robot

Fig. 4(a) describes a possible configuration of the robot that is composed of functionally partitioned modules such as driving modules, control modules, and NDT modules. Basically the robot is designed to have enough traction forces to climb the vertical pipelines or pull the tether cables, which are provided by two driving vehicles in front and rear of the robot. Each vehicle has flexible wheeled leg mechanisms pressing against the wall, respectively and the friction between the wheel and inside wall of the pipelines helps generate driving forces. During the forward navigation the driving vehicle in front of the robot generate traction forces and the vehicle in the rear side gives pushing forces, and vice versa. A driving vehicle consists of two vehicle segments and a steering mechanism between the segments. The other passive modules such as a control module and NDT modules are just linked via usual universal joints. The in-pipe robot communicates with the ground station by a specially designed tether cable. The tether cable is composed of power lines, optical fibers for video signal and the transmission of digital data. Recently, as a result of wireless approach, the intelligent in-pipe robot, which carries on energy-resource such as battery packs and can act autonomously, is presented, as shown in Fig. 4(b).

\section{Design of In-Pipe Robot According to Fittings}

Often, the shape and size of a robot are the most critical factors in determining maneuverability, which depend on the pipeline configuration. Pipelines basically consist of straight pipes running horizontally and vertically. There are also elbows, branches, reducers, and valves with unexpected mechanical damages such as dents, gouges, and the removed metals caused by third-parties, which are not reflected in the layout drawing and 
demands the highly flexible design of robots. Based on the considerations of the pipeline configuration, the requirements of design can be derived as follows:

1. active steering capability in branches

2. surmounting right angle elbow

3. driving through pipelines with a various diameter $( \pm 20 \%)$

4. sufficient traction forces (vertical load excluding self-weight)

Items from 1) to 3) provide the fundamental requirements for the mobility that the robot should have and prerequisite to negotiate through wide range of configurations of pipelines. Also, 4) describes the supplementary capabilities, which is necessary to carry out and perform useful tasks by using appropriate inspection tools such as CCD cameras and NDT units. Major design issues of the robotic system correspond to how to enhance mobility inside pipelines. The design of the system mainly depends on the present state of the art in technology as well as the requirements of the system. The configuration of pipelines restricts the whole size of the robot and the current technology determines the possibility of implementation because actuator, drive electronics, embedded controller, power supply, sensor, and communication tools would have to be placed in an extremely small space. From the present technological point of view, therefore, only a very large robot in size is possible. One reasonable solution to this problem is the use of articulated structure such as snakelike or multi--joint robots though the control of the robot gets more difficult.

\subsection{Wheel Leg Mechanism}

One of the most important issues in the design of a driving vehicle is how to obtain the traction force enough to pull instrumentation as well as the vehicle itself. Especially in vertical pipelines, it is desirable to keep adequate wall pressing forces in order to ensure sufficient traction forces. Excessive forces may dissipate power and be in danger of damaging the robot. On the contrary insufficient forces may cause the robot to fall down. On the condition that the wheel does not slip on the pipeline surfaces, the traction force is proportional to the friction coefficient and the pressing force between the wheel and the pipeline surface, and the friction coefficient depends on the material of wheel and the surface condition of pipelines. In addition, the link mechanism of the vehicle should minimize the variation of traction force caused by variation of pipeline diameters. Therefore, a leg mechanism has to meet the following three requirements. At first, it should be possible to push against the pipeline wall with adequate pressing forces. In the second, the pressing force should not show significant change during navigation in order to provide stable traction force and flexible locomotion. At last, the mechanism should be simple and small in size to occupy minimal space inside the pipelines. For example, the driving vehicle of MRINSPECT III has three wheeled legs circumferentially spaced 120 degree apart on the main shaft of the vehicle.

Fig. 5 illustrates the kinematic diagram of the wheeled leg mechanism of MRINSPECT III. The mechanism employs a pantograph mechanism with a sliding base that permits the natural folding and unfolding of the leg. Here, $l$ is the length of link, $\theta$ means the folding angle of the link measured by the rotary potentiometer, $K$ denotes the spring constant, $h$ represents the distance of the center of the wheel from the base. $F_{w}$ denotes the wall pressing force, $A_{x}$ and $A_{y}$ are the forces acting on the link by the spring, $x$ is the displacement of the sliding base. In the proposed mechanism when the wheels are pressed 
they just contract or expand along the radial direction. It is a very advantageous feature because undesirable distortion forces are not exerted on the robot when the robot goes over obstacles. Using Fig. 5 we can derive several basic equations necessary for optimizing the wall pressing forces. First the relation between $h$ and $x$ can be obtained as

$$
h=2 x \tan \theta=2 \sqrt{l^{2}-x^{2}} .
$$

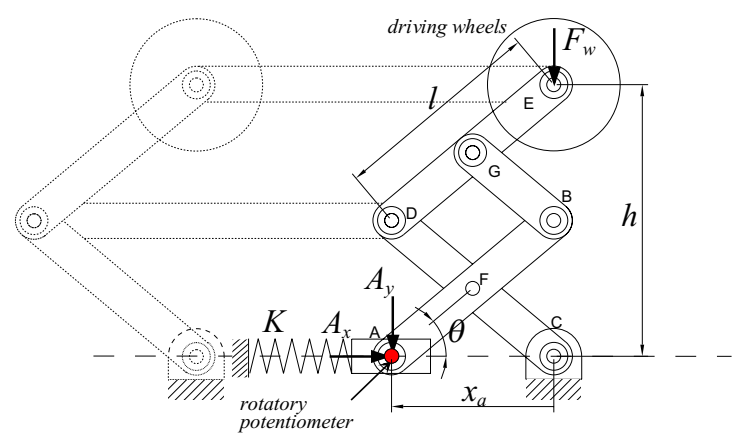

Figure 5. Wheeled leg mechanism of MRINSPECT III

When the link rotates by $\theta$, the radial force $A_{x}$ and the axial force $A_{y}$ acting on the spring are written by

$$
A_{x}=2 F_{w} \tan \theta, \quad A_{y}=0 .
$$

By using Eqs. (1) and (2), Eq. (3) will be derived.

$$
A_{x}=\frac{2 F_{w} x}{\sqrt{l^{2}-x^{2}}}=4 F_{w} \frac{l^{2}-h^{2} / 4}{h} .
$$

Now, let us differentiate Eq. (3) and derive spring constant $K$ at the operating point $x_{d}$ (8inch) which satisfies

$$
A_{x}=K\left(x-x_{o}\right)
$$

where $x_{o}$ denotes the initial displacement. Then, we have

$$
\begin{gathered}
K=\frac{2 F_{w}}{\sqrt{l^{2}-x_{d}{ }^{2}}} \frac{l^{2}}{l^{2}-x_{d}{ }^{2}}, \\
x_{o}=\frac{x_{d}{ }^{3}}{l^{2}} .
\end{gathered}
$$

Eq. (5) represents linearized spring constant and Eq. (6) denotes the initial length of the spring. Both are the basic equations for computing the wall pressing forces. By adjusting $K$ and $x_{o}$ properly, the wall pressing force with minimum variation can be obtained. 


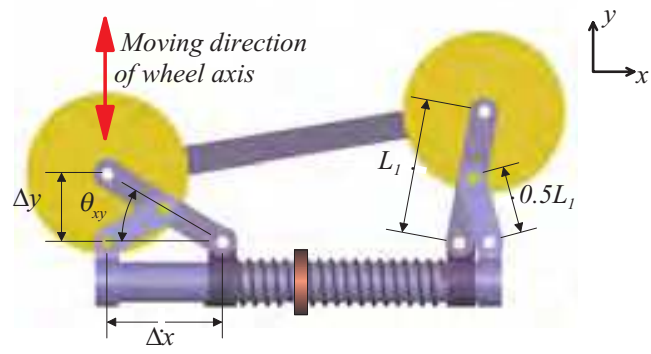

Figure 6. Wheeled leg mechanism of MRINSEPCT IV

Fig. 6 shows anther wheeled leg mechanism which is used for MRINSEPCT IV. In this mechanism, the distance between the central shaft and the wheel is determined according to the movement of the link, the elastic restoration force of the spring at the central shaft and reaction forces from the wall. From Fig. 6, the following equation can be derived.

$$
\Delta y=\Delta x \tan \theta_{x y}=\sqrt{L_{1}^{2}-\Delta x^{2}}
$$

where $x$ and $y$ denote the radial and axial directions, respectively. $L_{1}$ means the length of the crank, and $\theta_{x y}$ is the rotation angle of the linkage. $\Delta x$ and $\Delta y$ represent displacements along $x$ and $y$ directions, respectively. Because the radial displacement $\Delta y$ can be uniquely calculated by using the axial displacement $\Delta x$ according to Eq. (7), the force pressing the wall can be determined by adjusting the stiffness of the spring in the initial design stage and the traction force of the robot is determined accordingly. Kinematically, the asymmetric motion is not allowed when the front and rear wheel are constrained by the motor casing. In case of the MRINSPECT IV, however, the front and rear wheel set can move along radial direction independently because the axial displacement according to radial one is not so much large that the asymmetric motion is practically feasible. Since the mechanism has been designed to make the wheel have effective contact with the inside of pipelines and to cope with the variation of pipelines, the robot is adaptable to the uncertain pipeline conditions as well as provides sufficient traction forces during movements.

\subsection{Size of In-pipe Robot}

Pipeline configurations give geometric limitations and the size of a robot should be determined to satisfy the limitations. In an elbow, the robot can be modeled as a cylinder and relations can be derived among the diameter of the elbow, the curvature, and the size of the robot. The worst placement of the robot is when it is inclined with 45 degrees, as illustrated in Fig. 7(a).

In this situation, two different cases can be considered: (a) the diameter of the robot $D_{r}$ is relatively smaller than the height $h$, and both ends of the robot $p^{\prime}$ and $p^{\prime \prime}$ are located on the region of the straight pipeline. (b) Both ends of the robot are included in the elbow. Depending on the situation, constraint equations are derived to determine the size of the robot. In the case of (a), $D_{r}$ has the range of

$$
0<D_{r} \leq\left\{\left(r_{c}+\frac{d}{2}\right) \sin 45^{\circ}-\left(r_{c}-\frac{d}{2}\right)\right\} .
$$


The length of the robot $L_{r}$ is given by

$$
\left.L_{r}=2 \sqrt{2}\left\{\frac{d}{2}+r_{c}-\frac{d}{2}+D_{r}\right) \cos 45^{\circ}\right\} .
$$

Since $r_{c}$ is represented as $D$ in Fig. 7, the length of the robot $L_{r}$ is rewritten by

$$
\left.\frac{3}{2} \sqrt{2} D \leq L_{r}<3 \sqrt{2}-1\right) D
$$

In the case of (b), the range of $D_{r}$ is obtained by

$$
\left\{\left(r_{c}+\frac{d}{2}\right) \sin 45^{\circ}-\left(r_{c}-\frac{d}{2}\right)\right\}<D_{r}<D .
$$

Thus, the length of the robot $L_{r}$ becomes

and rewritten by

$$
L_{r}=2 \sqrt{\left(r_{c}+\frac{d}{2}\right)^{2}-\left(r_{c}-\frac{d}{2}+D_{r}\right)^{2}}
$$

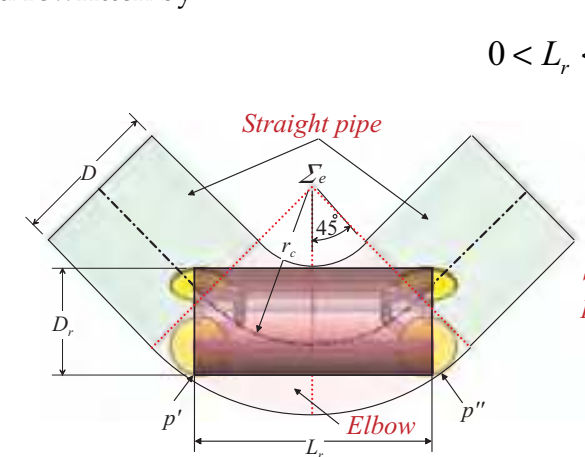

(a)

$$
0<L_{r}<\frac{3}{2} \sqrt{2} D
$$

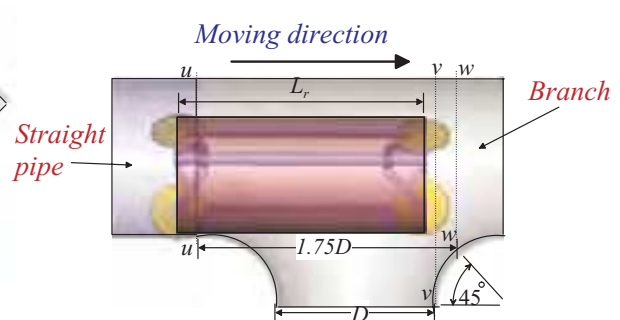

(b)

Figure 7. Size of the robot. (a) Size of the robot for negotiating the elbow. (b) Size of the robot for negotiating the branch

Eqs. (8), (10), (11), and (13) provide the basic constraint equation so that the robot can moves in pipelines connected with elbows. The details can be referred to (Choi \& Ryew, 2002).

In the branch, the size of the robot determines whether turning is possible or not. For example, when the length of the robot is a little longer in Fig. 7(b), the robot cannot turn in the branch though the robot has the proper size for moving in the elbow. When the front wheel set of the robot is placed in the branch and the rear wheel set has contact with the inner side of the straight section of the pipeline, the rear wheel set is confined absolutely to the straight section of the pipeline. The rear wheel set is kept from steering though the robot tries to turn. Thus, to turn in the branch, the rear wheel set should pass over the line $u-u$ from which the area of the branch is. The robot should start turning before the front wheel set reach the line $v-v$. If the front wheel set passes over the line $v-v$ and the robot tries turning, then separation and isolation will occur. However, the robot can turn in the branch until the front wheel set reaches to the line $w$ - $w$ if the body of the robot except wheels does not have contact with the wall. Therefore, the length of the robot should be shorter than $1.75 \mathrm{D}$. On the other hand, the robot could turn easily but could not drive straightly because it would be isolated 
in the turn drive space if the length of the robot is shorter than the diameter $D$ of the pipeline. Thus, the length of the robot $L_{r}$ for negotiating branch is given by

$$
D<L_{r}<1.75 D \text {. }
$$

Consequently, to determine the useful length of the robot in the elbow and the branch, Eqs. (10), (13) and (14) should be incorporated. From Eqs. (10), (13) and (14), $L_{r}$ can be determined with Eq. (14) since $D_{r}$ in Fig. 7 is flexible.

\section{Geometrical Analysis and Behavior of In-Pipe Robot in Fittings}

The geometries of pipelines are relatively simple because their dimensions and configurations are regulated by law. It is sure to be an advantageous aspect in developing an in-pipe robot, but there are several intrinsic problems to be considered in the design of the in-pipe robot, especially its size. Since the inside of a pipeline is narrow and rigidly constrained, the size of the robot is not allowed to be excessively large or extremely small, which is determined depending on that of the pipelines. The inside of pipelines is a threedimensionally curved surface even in the case of straight one and furthermore, the situations are getting more complicated in the fittings. Thus, it is required to know the geometric configurations of them. In this section we present the geometrical model of elbow and branch. After analyzing the moving paths of the in-pipe robot, strategies for moving in the fittings are proposed.

\subsection{Geometrical Analysis of Elbow}

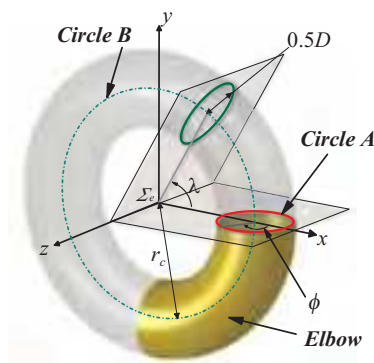

Figure 8. Geometry of the elbow

As illustrated in Fig. 8, an elbow with its diameter $D$, since it is similar to a part of a torus, is generated by rotating a Circle $A$ of the diameter $D$ around a given axis. Let us set a coordinate frame $\sum_{e}$ at the center of the torus such that the $z$-axis is along the axis of rotation of $A$, and the other two orthogonal axes $x$ and $y$ are set along the radial directions. The Circle $B$ with the radius of $r_{c}$, means the trace of the center of $A$ generated by rotating $A$ along the $z$-axis. According to the regulation of pipeline supply equipments, $r_{c}$ should be 1.5 times larger than the diameter of $A$ such as $r_{c}=1.5 D$. Thus, the mathematical representation of the elbow geometry $P_{e} \in R^{3}$ can be written by 


$$
P_{e}(\phi, \lambda)=\left[\begin{array}{c}
\left(r_{c}+0.5 D \cos \phi\right) \cos \lambda \\
\left(r_{c}+0.5 D \cos \phi\right) \sin \lambda \\
0.5 D \sin \phi
\end{array}\right] .
$$

where $\phi$ is the parameter representing the polar location of the pipeline wall on $A$ from the $x$ axis and, denotes the latitude angle of Circle $A$ as represented in Fig. 8.

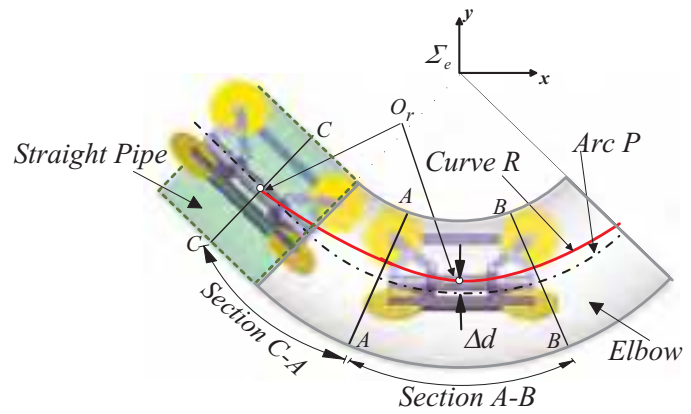

Figure 9. Behavior of the robot entering the elbow

In Fig. 9 the movements of the robot in the elbow, simplified with wheels and linkages, are simulated using a three-dimensional graphical tool. Section $C-A$ is a transition region where the center of the robot moves from the straight pipeline to the elbow, while the robot completely enters into the elbow in the section A-B. Curve $R$ represents the moving paths of the center of the robot represented with $O_{r}$, and $\operatorname{Arc} P$ corresponds to the section of the Circle $B$ included in the elbow as shown in Fig. 9. It can be noted that Curve $R$ does not always coincide with $\operatorname{Arc} P$ because the wheels of the robot with finite width have threedimensional contact with the curved inner surface of the elbow. The difference between $A r c$ $P$ and Curve $R$ designated with $\Delta_{d}$, changes while the robot goes through the elbow and also, it depends on the axial posture of the robot in the elbow. The location of the legs with wheels around the central axis of the elbow represented with Circle $B$ is called the axialposture in this chapter, and it plays a significant role on controlling the steering direction of the robot in the branch. In the elbow, since the traces of wheels have different curvatures depending upon the contact points of the wheels with the walls, the largest velocity of wheels in the elbow may be required to be 1.8 times faster than the smallest one in the extreme case. Thus, it is strongly demanded to accurately modulate the velocities of wheels. Or, it may give quite detrimental effects on the overall performance of the robot because some of wheels are inevitably forced to slip and the driving system may be in danger of being overloaded during movement. In this reason, MRINSPECT IV is developed to carry out moving in elbows by modulation the speeds of driving wheels.

\subsection{Geometrical Analysis of branch}

Movements of the robot in the branch is more difficult than in the elbow because the geometry of the branch can not be expressed as closed form equations and additional considerations are required depending on the direction of moving. 


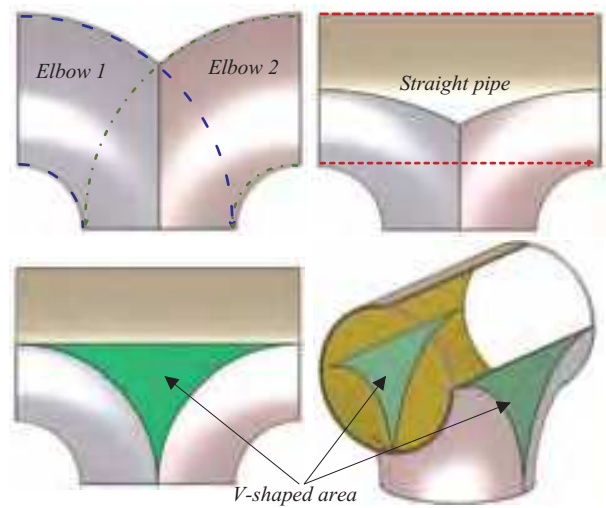

Figure 10. Geometrical analysis of the branch

As shown in Fig. 10, a branch can be considered to be built by putting together several patches with simple geometrical shapes such as elbows, straight pipelines and flat patches. The flat patch, called $V$-shaped area in this chapter, is located between the elbows. It can be noted that it is too complicated to get a mathematical expression for the geometry of the branch. The characteristic situations which the robot experiences on moving in the branch are briefly illustrated in Fig. 11.

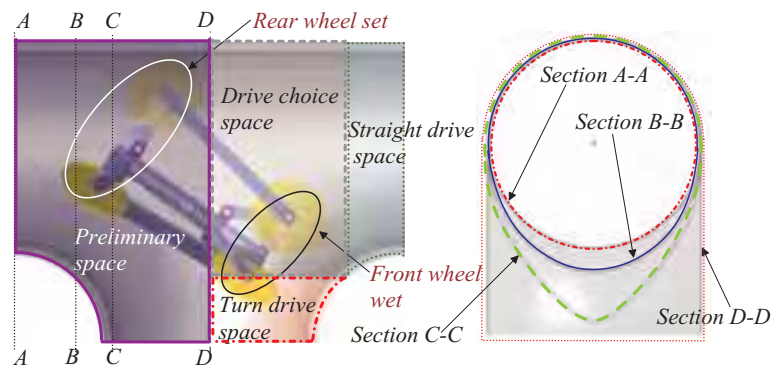

Figure 11. Constraint space in the branch

Assuming that a robot has the wheeled leg same to that of MRINSPECT IV. The space in the branch can be divided into four regions with boundaries such as $A-A, B-B, C-C$ and $D-D$. A$A$ is the end of the region with the regular diameter $D, B-B$ means the intermediate one, $C-C$ represents the region where the cross section expands infinitely as illustrated in Fig. 11. D-D is the center line of the branch. On entering the branch the diameter of the pipeline initially does not change a lot until the front wheel set reaches the line $B-B$ after passing through the line $A-A$. The robot still cannot turn in this region regardless of the difference of wheel speeds. When the front wheel set approaches to the line $C-C$, the diameter of the pipeline changes considerably and the robot goes straight. However, it can not still turn actively because the front wheel set has contact with the inner surface of the pipeline and the rear wheel set is entirely constrained in the inner surface of the pipeline. In this situation, wheels just slip on the inner surfaces of the pipeline whenever it tries to turn with differences of the wheel velocities. This space is called the preliminary space because the robot is ready to turn or drive forward. When the front wheel set is close to the line $D-D$, either one or two wheels placed in the region, called turn drive space, loses contact with the inner surface of the 
pipeline. This space is called drive choice space because the robot is able to choose the direction of moving, e.g. turning or going forward. It can turn toward the designated direction if speeds of wheels are adequately modulated. Though the method in the elbow may be partly employed on traveling through the branch, there are several characteristic features requiring the method dedicated to the branch as follows.

1) As the robot proceeds to turn in the branch, the front wheel set and the rear wheel set may be folded or unfolded, respectively as shown in Fig. 12. Thus, light slips in the contact points are inevitable, which are more severe in the $V$-shaped area.
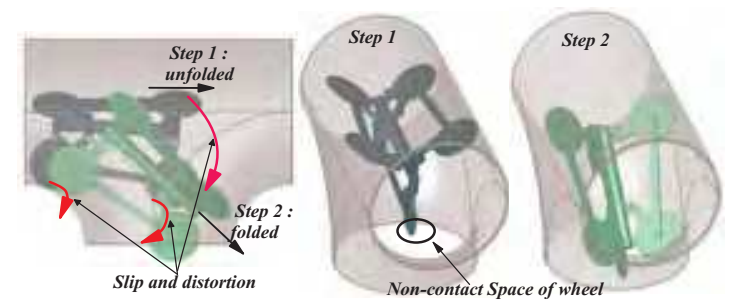

Figure 12. Characteristic features of movement in the branch

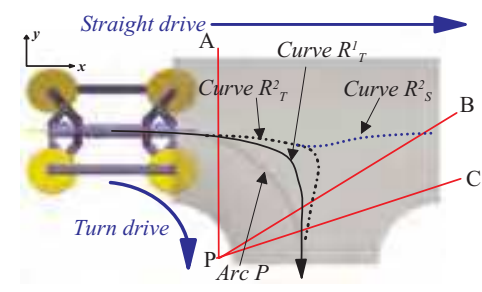

(a)

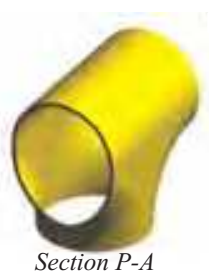

Section $P-A$

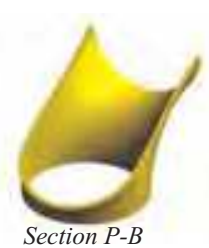

(b)

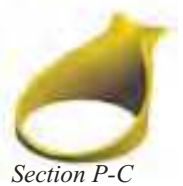

Section $P-C$

Figure 13. Moving path in the branch and corresponding regions. (a) Moving path. (b) Corresponding change of cross sections

2) As shown in Fig. 12, some of the wheels lose contacts with the wall and it is not valid any more the assumption that six wheels have contacts with the wall in the branch.

3) As shown in Fig. 13, the robot meets a wide variety of cross sections when it turns in the branch, which is not in the case of the elbow. Depending on the direction of turning, the influence of gravity changes and the paths of turning do accordingly. In Fig. 13, the paths of turning are simulated, where Curve $R^{1}{ }_{T}$ and Curve $R^{2}{ }_{T}$ are the paths according to the directions of gravity such as $-y$ and $+y$, respectively.

4) The paths of turning are not deterministic and change considerably depending on the direction of entrance as illustrated in Fig. 14. For example, Curve $R^{3}{ }_{T}$ for entering from the side opening is much different from Curve $R^{4}{ }_{T}$ in the case of the middle one. The characteristic features aforementioned imply that the robot basically should be controlled according to the method different from that of the elbow when it travels in the branch. The paths of moving in the elbow are deterministic because they are produced by the wheels of the robot while they keep contact with the inner wall of the elbow. Those in the branch, however, are not deterministic because the wheels not only slide but some of them do not keep contact with the wall at times. 


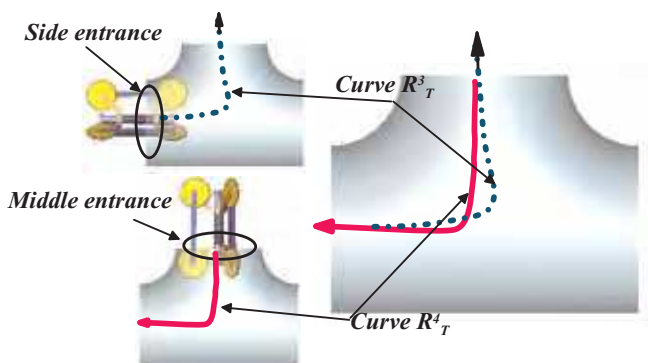

Figure 14. Paths of turning depending on the entrance

\section{MRINSPECT series}

\subsection{MRINSPECT III}

The MRINSPECT III, as shown in Fig. 15(a), is composed of three vehicles which are a front driving vehicle, a control module, a rear driving vehicle, and inspection tools. Each driving vehicle has a front segment and a rear segment. Two vehicle segments and a steering mechanism called the Double Active Universal Joint (DAUJ) with clutch between the segments, as shown in Fig. 16

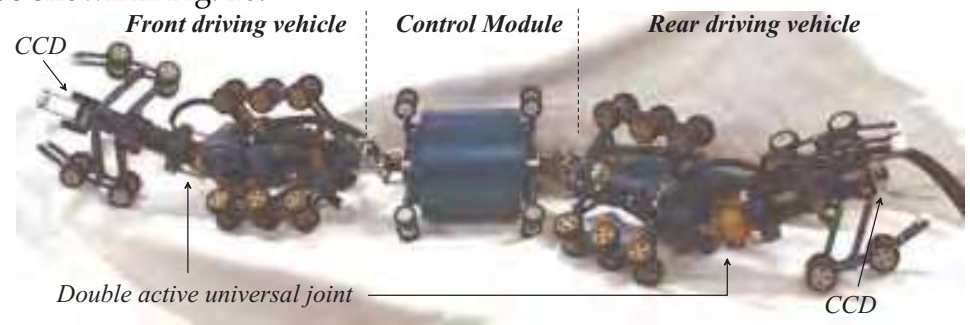

(a)

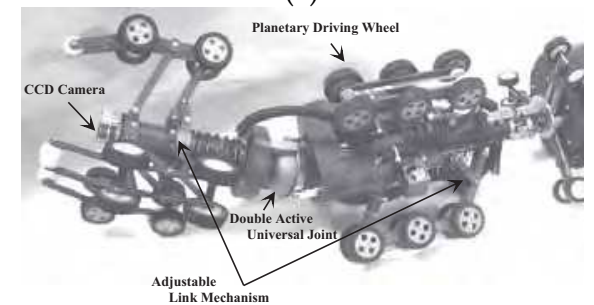

(b)

Figure 15. MRINSPECT III. (a) Articulated configuration. (b) Driving vehicle

This robot is configured as an articulated type where two independent vehicles are connected via a double active universal joint providing omni-directional steering capability. DAUJ acts like a stiffness controllable two-DOF joint and the joint makes it possible to control the compliance of active joints in steering. DAUJ has a gear-bearing-gear system, and an inner and an outer universal joint to prevent each segment from rolling. Without the universal joints, the gear heads are free to move with respect to each other upon a bearing which lies on a plane tilted $\phi$ degrees from the perpendicular planes of each gear axis of rotation. DAUJ is able to yaw and pitch $\pm 2 \phi$ degrees, and rolling is prohibited by the inner 
and the outer universal joints. Thus, it prevents the segment from rotating along the axial direction and the trails of pressing wheels on the wall of the pipeline can be preserved continuously. Otherwise the vehicle may be in danger of twisting during steering. Also, it has the advantage that the electrical cables such as power or signal lines are free from twisting and thus, wire harness can be quite simplified. Each articulated body of the robot has three wheeled legs located circumferentially 120 degrees apart. The legs employ a pantograph mechanism with a sliding base that ensures natural folding and unfolding of the body. With the mechanism the legs just contract or expand along the radial direction when they are pressed. It is a quite advantageous feature because undesirable forces causing distortion does not exert on the body when the robot goes over obstacles such as steps, reducers, protrusions inside the pipelines. The driving motor of the vehicle is included in the rear articulated body which gives the major driving force to the system. The front body does not have any power and it just guides the motion. The wall pressing forces are obtained by the reflective forces of the spring that supports the moving base of the pantograph mechanism. Thus, the wall pressing forces can be easily preset depending on the payload by adjusting the spring constant and initial deflection.

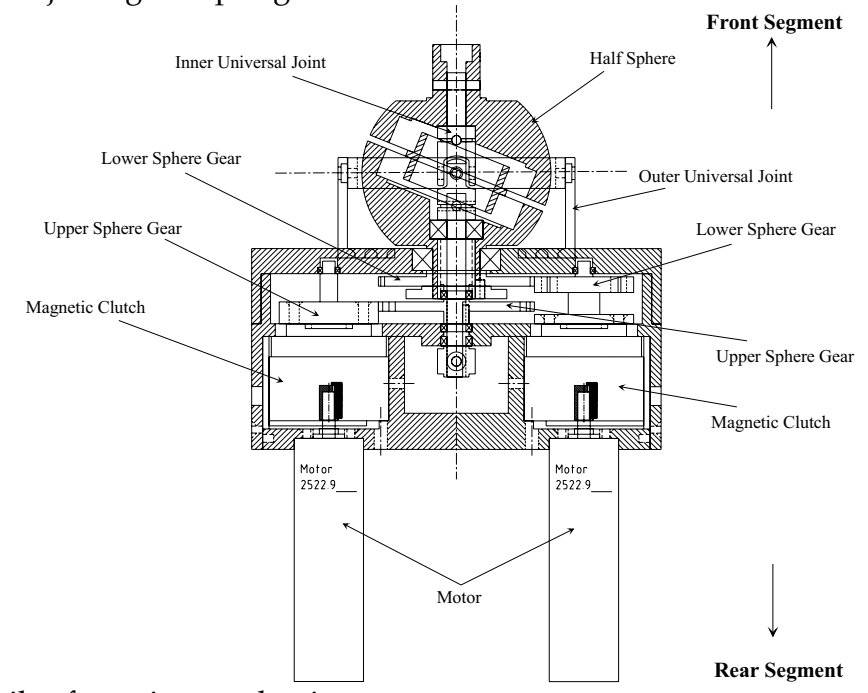

Figure 16. Details of steering mechanism

Fig. 17 illustrates Graphical User Interface in the ground station for controlling the robot. GUI uses Widows as the platform and coded with Visual $\mathrm{C}++$. It provides information about the motion, CCD images of front and rear sides, operation menus such as speed, steering angle, etc., which can be commanded in real-time by the operator, and virtual map describing the configuration of the traversed pipelines. In fact, the proposed robot has additional sensors to detect the direction of gravitation. With these sensor readings and the measured steering angles, the configuration of the pipelines can be estimated. By the results of the estimation we can construct a 3D graphical model representing the configuration of pipelines called Virtual Map. Thus, elbows, straight pipelines and other characteristic features such as diameter variation, inclination or mechanical damages etc., can be easily figured out by just traversing the robot inside the pipelines. 


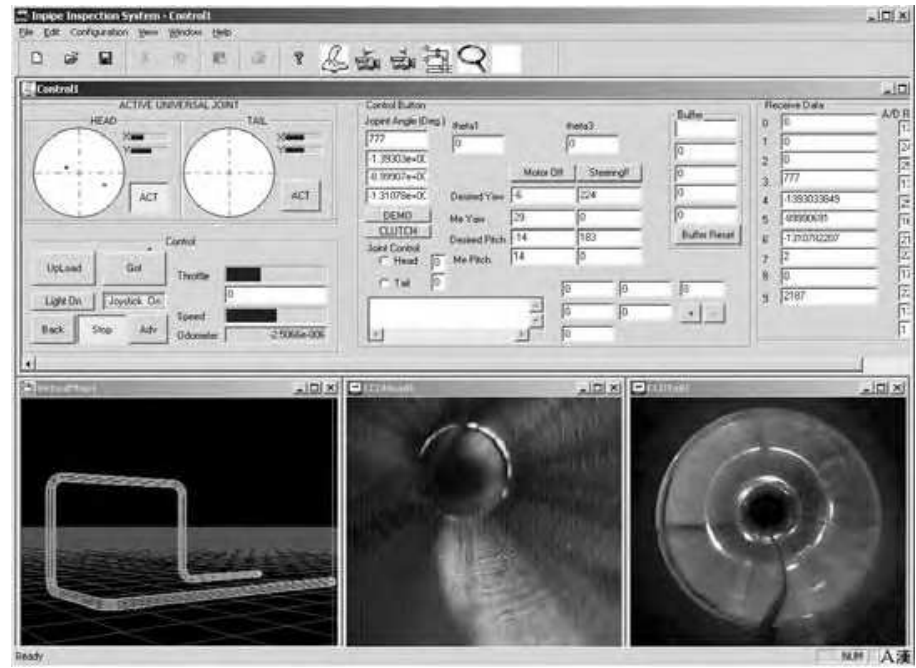

Figure 17. Graphical User Interface

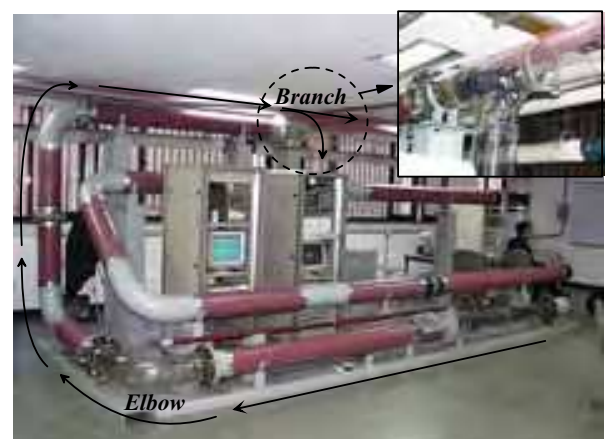

Figure 18. Testbed for MRINSPECT III

Most of experiments for MRINSPECT III have been carried out in a testbed for 8 inch urban gas pipelines (total length $26 \mathrm{~m}$ with horizontal and vertical pipelines, several elbows, a branch, a full-bore valve) shown in Fig. 18. The testbed has been constructed for developing and testing of various in-pipe inspection systems and the arrow lines denote the path that the proposed robot traversed. The small box in Fig. 18 enlarges the branch included in the testbed where the steering capability of the robot was evaluated.

As shown in Fig. 19(a), while the robot changed the direction of navigation in the branch, DAUJ behaved like a stiffness controllable two-DOF joint. Thus, though it had contact with the rigid wall of the pipeline, it is bent like a spring and achieved the natural steering motion. On the contrary, when it is required to pass by a branch as shown in Fig. 19(b), DAUJ acts like a rigid joint by making the clutches completely " $\mathrm{ON}^{\prime}$ " state and prevents the robot from falling into the bifurcated pipeline. In the autonomous mode, the clutches are in "OFF" states and the torques from the steering motors are cut off. As shown in Fig. 19(c), when it was running through the elbows or pipelines without bifurcation, DAUJ acted like a usual universal joint. In this case the active steering is not required because the geometric configuration of pipelines guides the robot. 


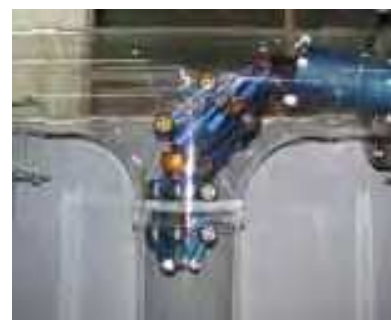

(a)

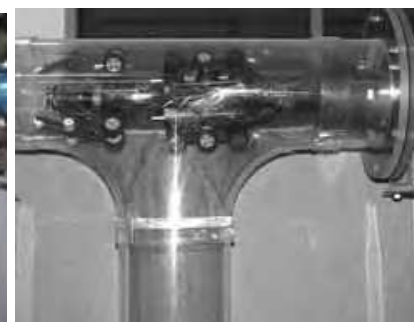

(b)

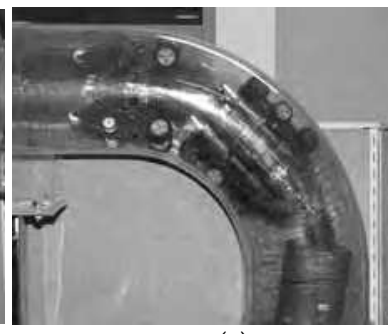

(c)

Figure 19. Experiment in fittings. (a) Steering in the branch. (b) Strait drive in the branch. (c) Navigation in the elbow

\subsection{MRINSPECT IV}

As depicted in Figs. 20 and 21, MRINSPECT IV largely consists of three parts, called body frame, driving module, and CCD assembly. Three driving modules are attached at the distal ends of foldable legs of the body frame and they are located circumferentially 120 degrees apart from each other. The CCD assembly is mounted in the front side of the body frame.

The radial dimension of the robot is changeable from 85 to $109 \mathrm{~mm}$, while the axial one is 150 $\mathrm{mm}$ constant as illustrated in Figs. 22(a) and (b). Also, the robot can exert $9.8 \mathrm{~N}$ of traction force and $0.15 \mathrm{~m} / \mathrm{s}$ of speed in maximum just with $0.7 \mathrm{Kg}$ of its own weight.

As illustrated in Fig. 23(a), the body frame is a skeletal linkage mechanism the other components such as driving modules and CCD assembly are attached to. It is composed of two sets of slider-crank mechanisms in the front and rear side of the robot, respectively, where each set consists of three slider-crank mechanisms located equidistantly along the circumferential direction. Couplers of slider-crank mechanisms in the front and the rear side of the robot are connected each other with driving modules as shown in Fig. 23(b). Radial motions of wheels are synchronized with a ringlike slider illustrated in Fig. 23 and its axial motion is limited with a stopper in the central shaft. The front wheels and the rear ones, called front wheel set and rear wheel set, respectively in this chapter, are allowed to move radially in an asymmetric fashion as shown in Fig. 22(c). Three driving modules are attached at the ends of the legs on the body frame as depicted in Fig. 21.

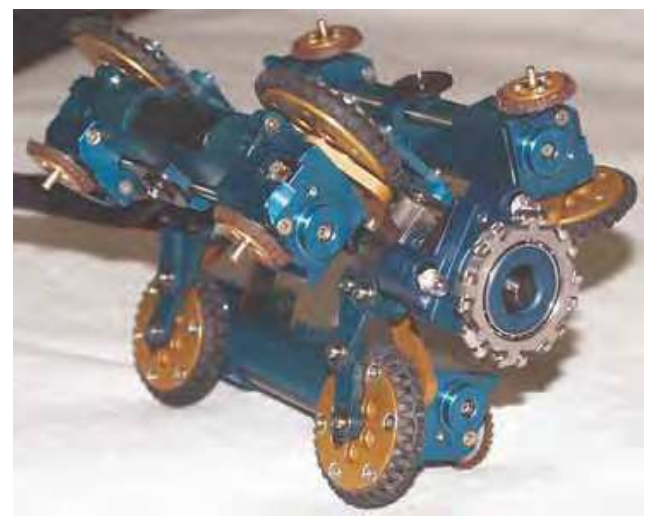

Figure 20. Photo of MRINSPECT IV 


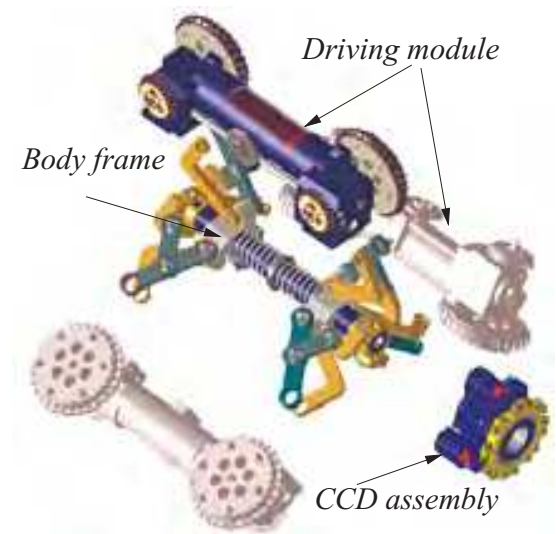

Figure 21. Exploded view of MRINSPECT IV

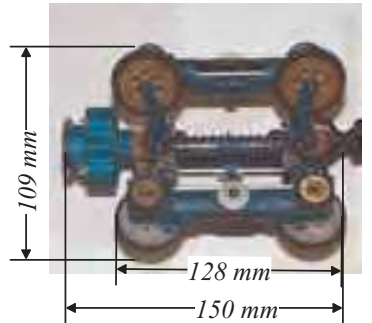

(a)

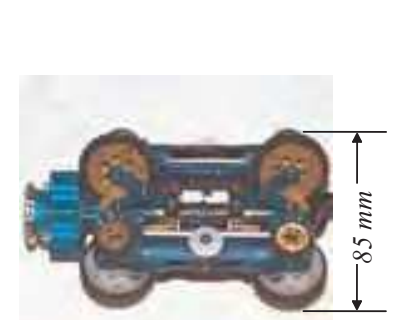

(b)

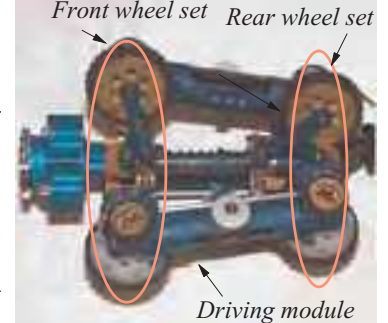

(c)

Figure 22. Flexible link mechanism. (a) Maximum radial dimension of MRINSPECT IV. (b) Minimum radial dimension of MRINSPECT IV. (c) Asymmetric movement of MRINSPECT IV

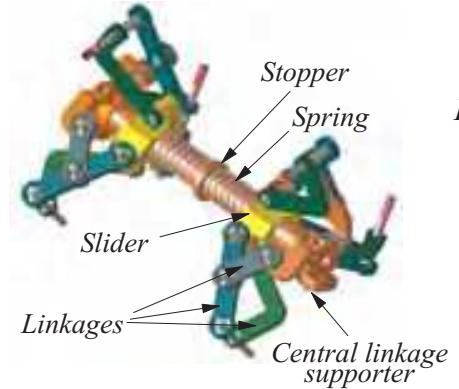

(a)

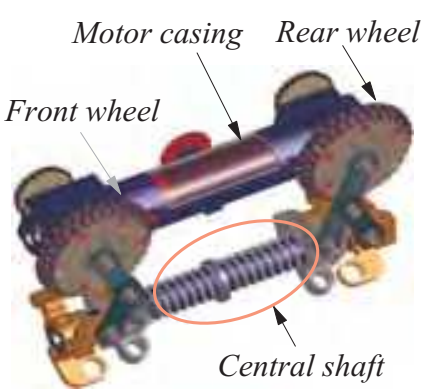

(b)

Figure 23. Link mechanism. (a) Linkage configuration. (b) Wheeled leg

The driving module largely consists of a geared DC motor (Maxon, 4.5W) with an encoder, several wheels, gears, and casings as shown in Fig. 24(a). The front wheel and the rear one are driven with a single motor via gear transmission as shown in Fig. 24(b), where $\omega$ 's denote the vectors for the rotating directions of the transmission units. As the driving module is designed to be easily disassembled from the body frame, the convenience in maintenance is ensured. Driving modules, since they are independently controlled, amplify traction forces, which let the robot have sufficient traction forces on moving upward in the vertical pipelines. 


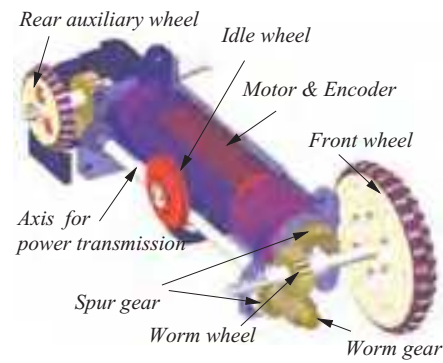

(a)

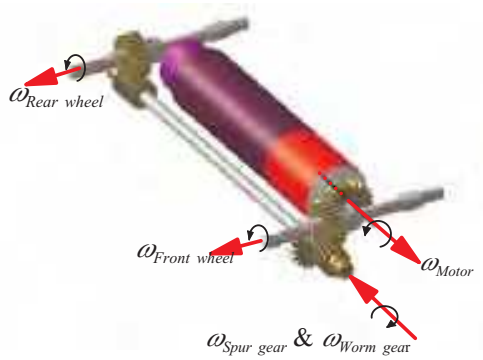

(b)

Figure 24. Driving module. (a) Outline of the driving module. (b) Details of power transmission mechanism

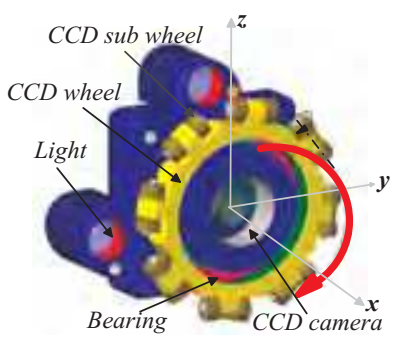

Figure 25. Construction and function of CCD assembly

As shown in Fig. 25, the CCD assembly is composed of a CCD camera, lamps for illumination, a frame and an additional mechanism, called CCD wheel set. The CCD wheel set includes CCD wheel rotating along the circumferential direction and eight couples of $C C D$ sub wheel located on $C C D$ wheels and capable of rotating along their own axes. Because the CCD sub wheels are

capable of rotating circumferentially as well as along its own axes, it helps the robot slide on the wall during steering in the fittings and prevents the body of the robot from having direct contact with the wall so that the robot may not be stuck in the pipeline and guide it to the desired direction.

MRINSPECT IV can be steered and driven at the same time only with a driving module by adopting a concept of the differential driving algorithm that allows controlling each driving wheel individually; no additional steering module is necessary MRINSPECT IV steers its own body with the velocity differences among the driving modules (Roh \& Choi, 2002; Roh \& Choi, 2005).

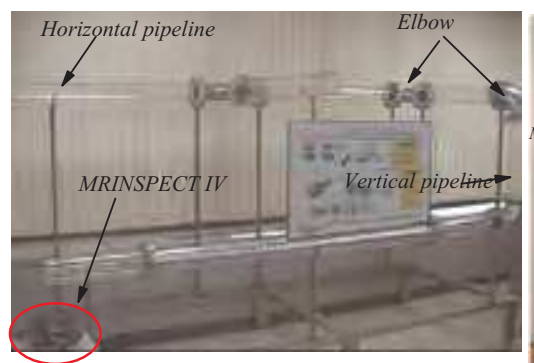

(a)

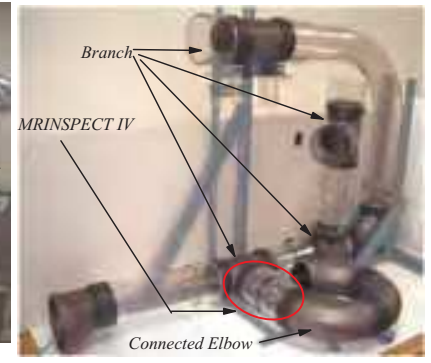

(b)

Figure 26. Testbeds. (a) Testbed for preliminary experiment. (b) Modular testbed for advanced experiment 
The experiments were carried out in the test bed shown in Fig. 26, where Fig. 26(a) was for the preliminary test and Fig. 26(b) was for the experiments in fittings. For ease of observation pipelines were made of transparent plastics with several off-the-shell parts, and various experiments could be performed by reconfiguring the components of the testbed.

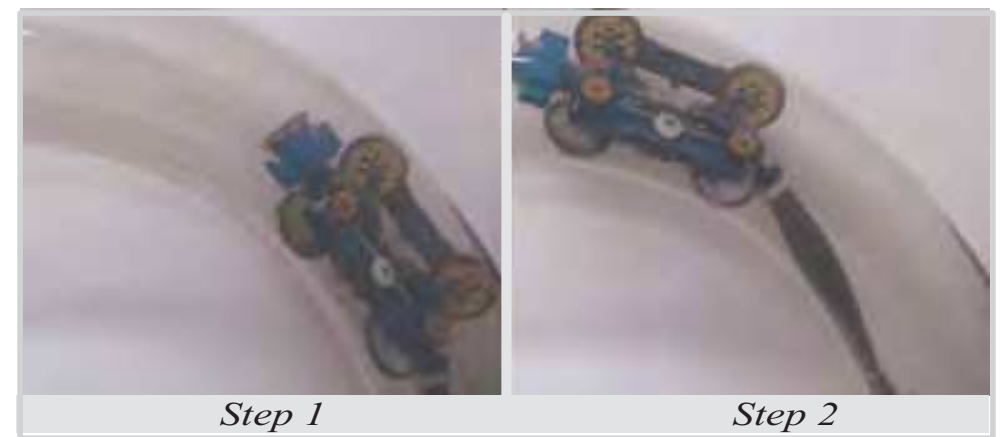

(a)

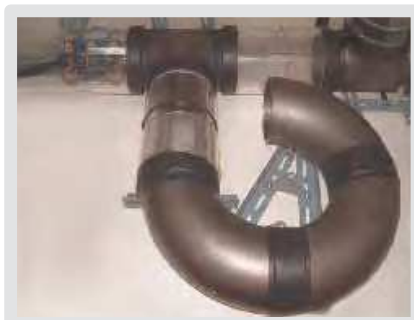

Step 1

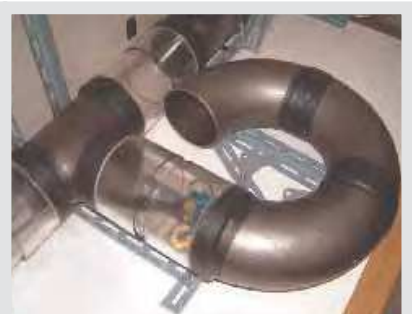

Step 2

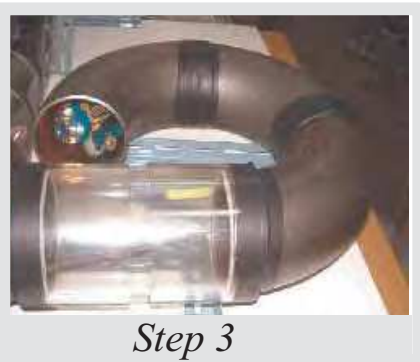

Step 3

(b)

Figure 27. Navigation in the elbow. (a) Robot in the transparent elbow. (b) Test for drive performance in the elbow

Fig. 27(a) represents the experimental scenes when the robot moved along the elbow. Its maximum speed of moving was $0.15 \mathrm{~m} / \mathrm{s}$ while controlling velocities. Fig. 27(b) shows the second experiments where the robot traveled in the special pipelines composed of three elbows continuously welded. To prove the effectiveness of the proposed method, the power consumption was measured when the control method was applied or not, respectively. When the velocity was not controlled, about $10 \%$ more power was consumed and it is because the robot was overloaded due to slippage of wheels. It can be concluded that the speed modulation of the differential drive robot is very much important on moving in the elbow.

Movements in the branch are largely classified into two cases such as straight drive and turn drive as depicted in Fig. 28. The straight drive is simple to realize comparing to the turn drive since all the driving wheels just need to have the same speeds. The turn drive in the branch is largely classified into two cases as shown in Fig. 29 according to the entrance of the branch the robot approaches. Also, two cases in Fig. 29 are divided into ten subcases according to the relative placement of the branch with respect to the direction of gravity. In fact, the turn 
drive is possible without considering the direction of gravity in the case of 1 and 2, while the direction of gravity should be taken into consideration in the other cases. In Figs. 30 and 31, the experimental scenes for these cases are shown. All the cases have been proven to be successful. It has been shown that the turn drive could be accomplished just by the triggering force generating the driving momentum along the commanded direction.

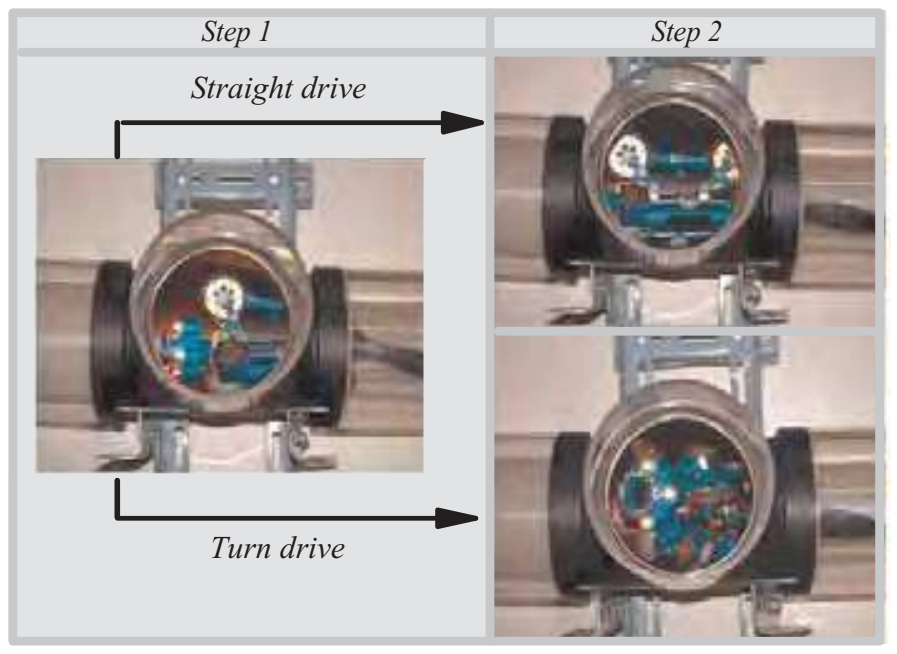

Figure 28. Comparison with straight drive and turn drive in the branch

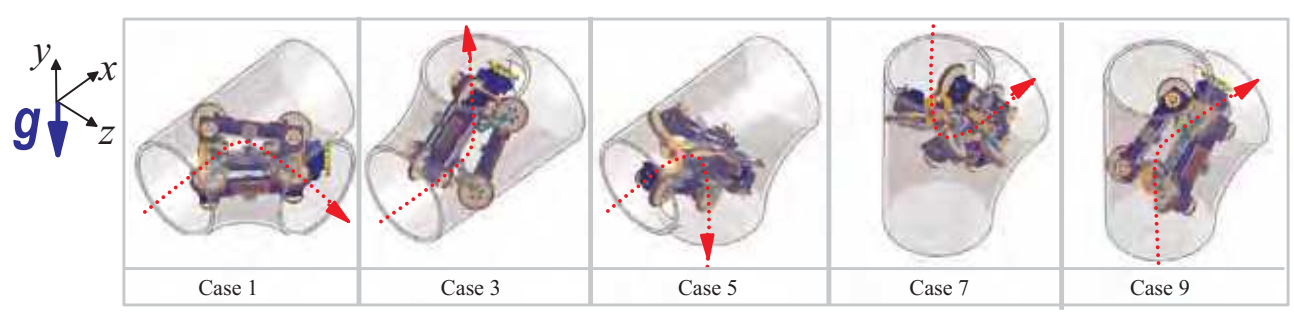

(a)

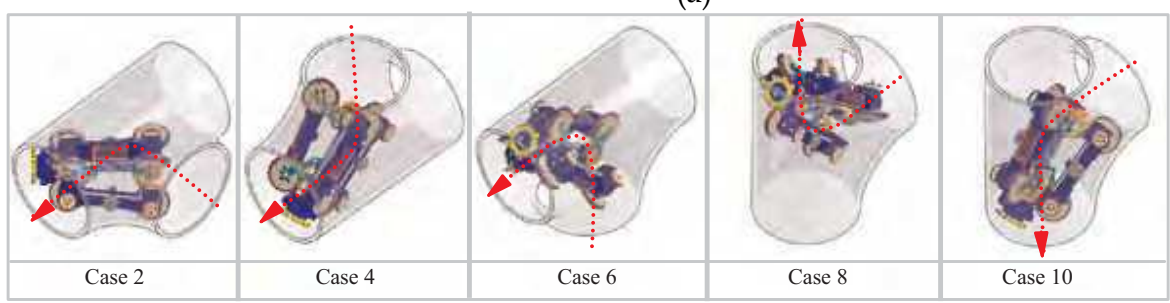

(b)

Figure 29. Classification of turn drive according to the placement with respect to the direction of gravity. (a) Turn drive from the side entrance. (b) Turn drive from the middle entrance 


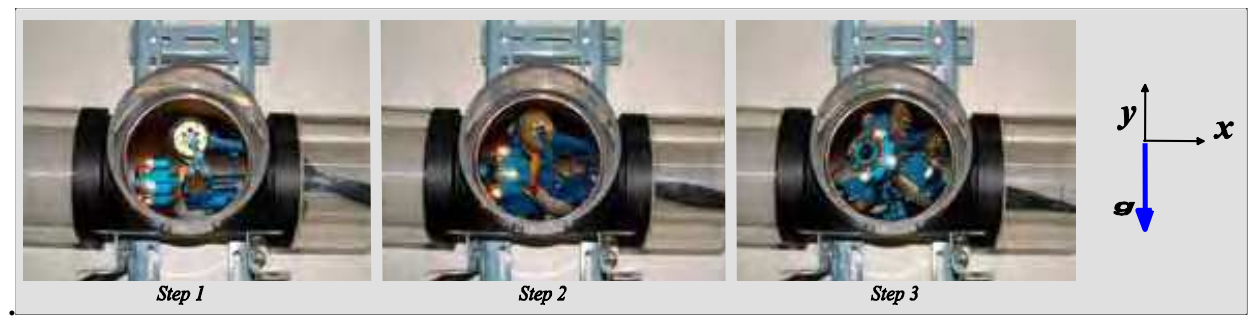

(a)

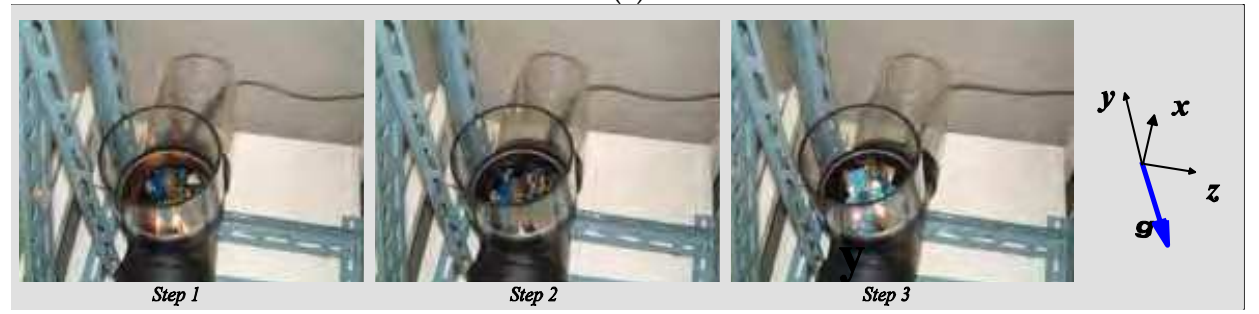

(b)

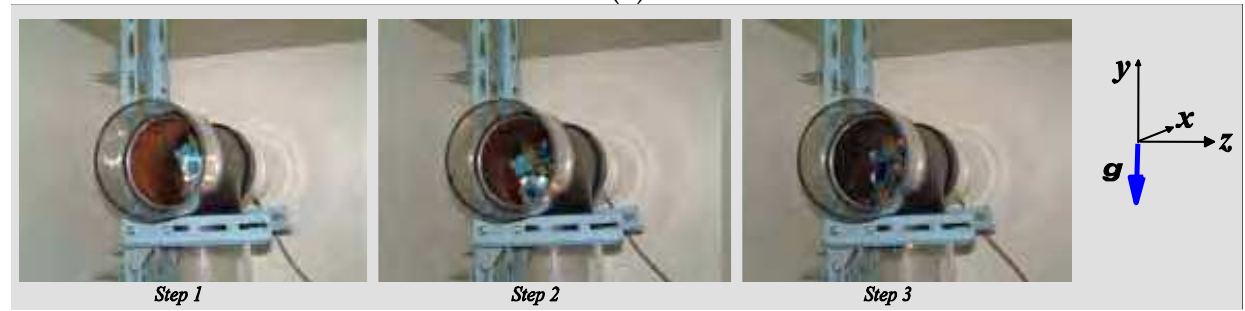

(c)

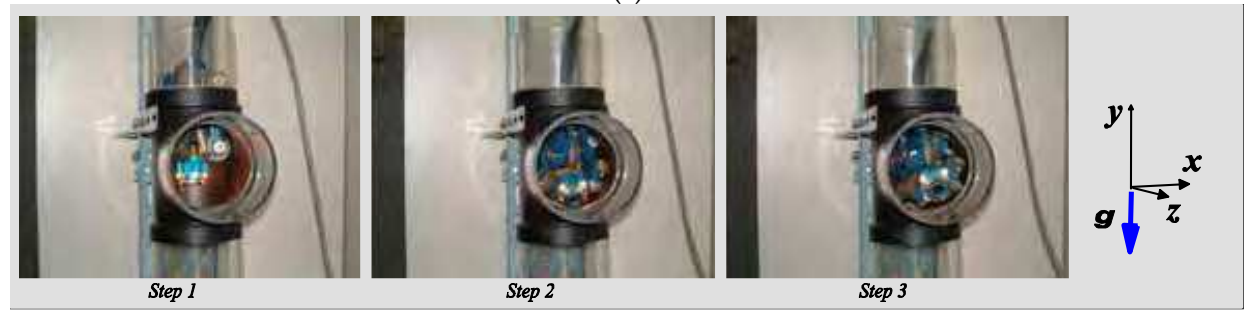

(d)

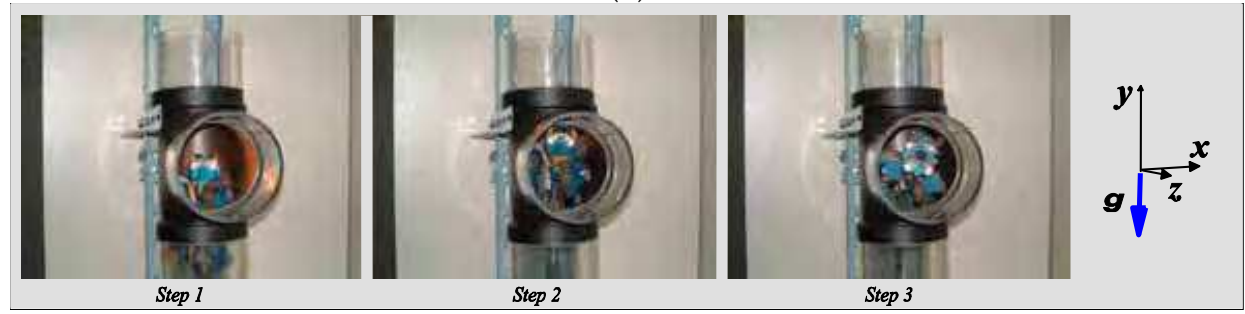

(e)

Figure 30. Experiments on turning in the branch. (a) Case 1. (b) Case 3. (c) Case 5. (d) Case 7. (e) Case 9 


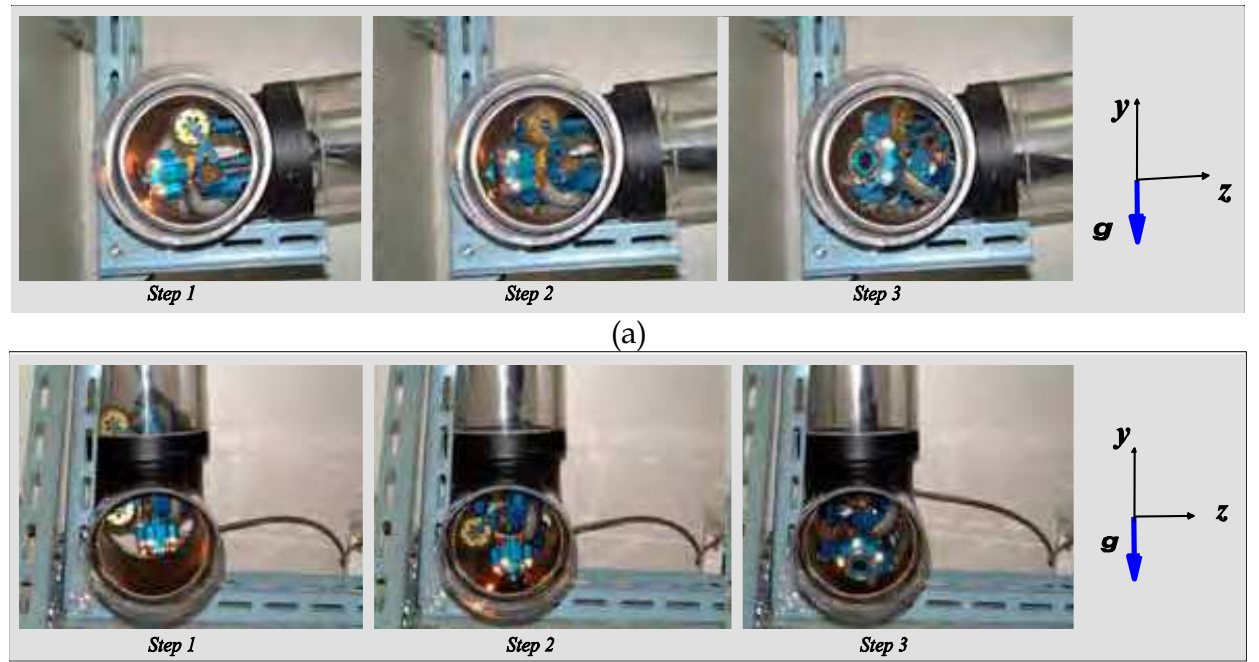

(b)

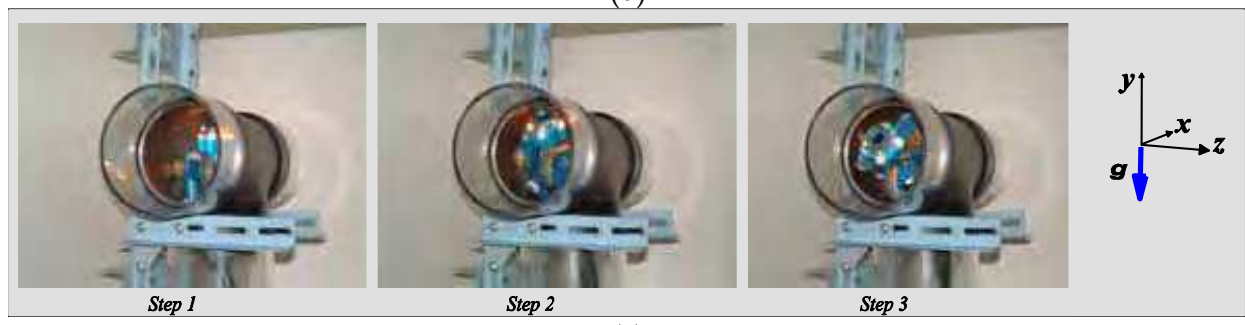

(c)

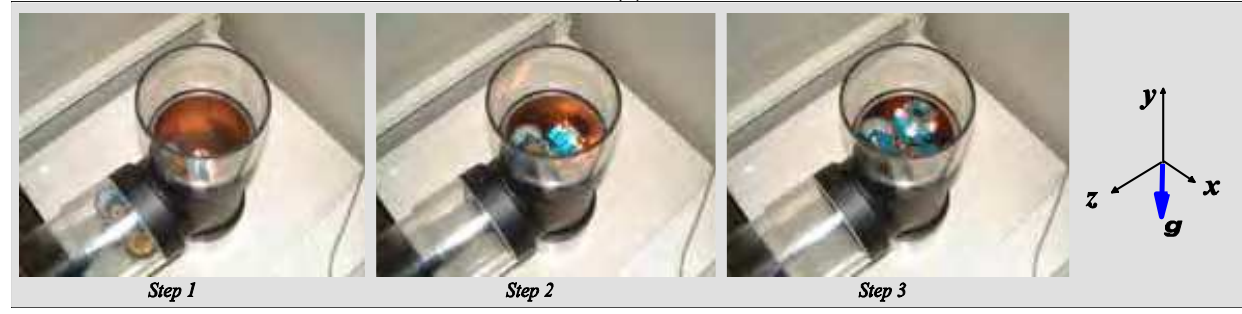

(d)

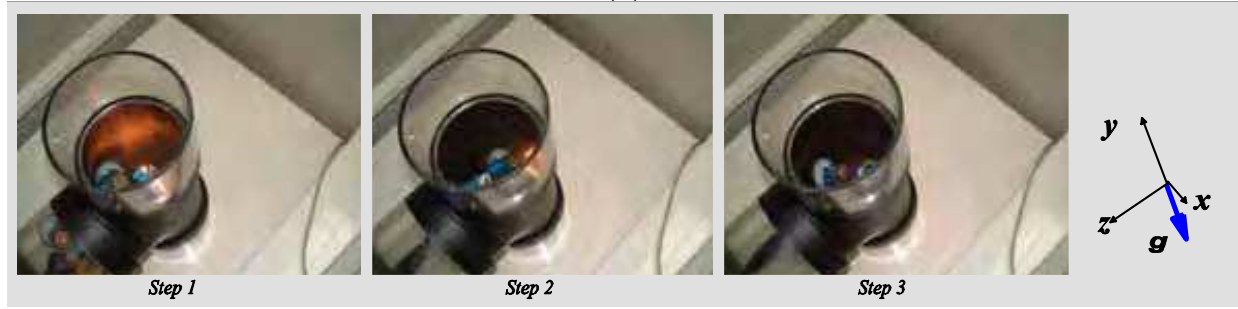

(e)

Figure 31. Experiments on turning in the branch. (a) Case 2. (b) Case 4. (c) Case 6. (d) Case 8. (e) Case 10 


\subsection{MRINSPECT V}

MRINSPECT V is the fifth model of MRINSPECT Series that we are developing recently. Since the development of the robot is not accomplished, we briefly overview the robot. MRINSEPCT V equips with a mechanical structure similar to that of MRINSPECT IV where differential driving can be implemented. Furthermore MRINSPECT V improves a power transmission mechanism of a driving unit as well as mobility and driving efficiency inside pipelines by applying a concept of the selective driving algorithm, which is a new clutchbased driving algorithm.

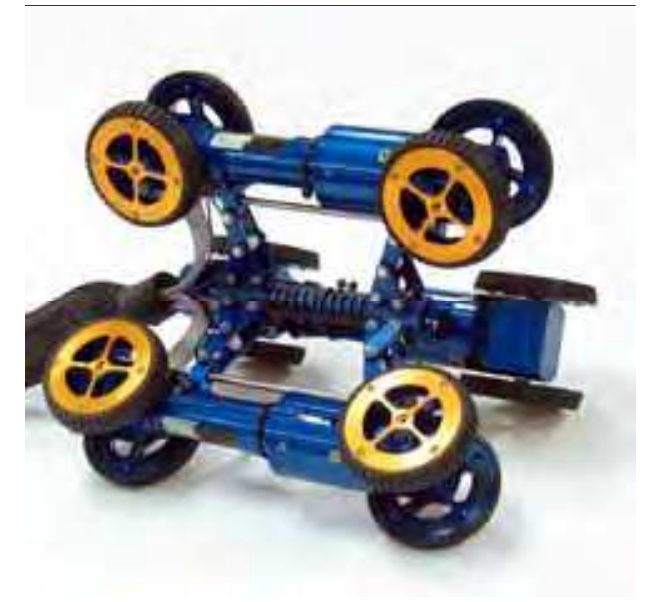

Figure 32. Photo of MRINSPECT V

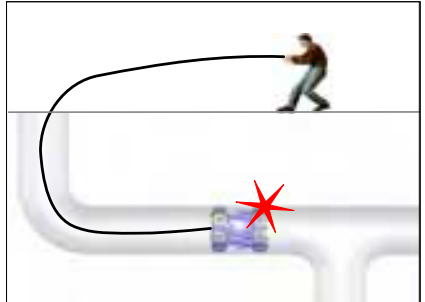

(a)

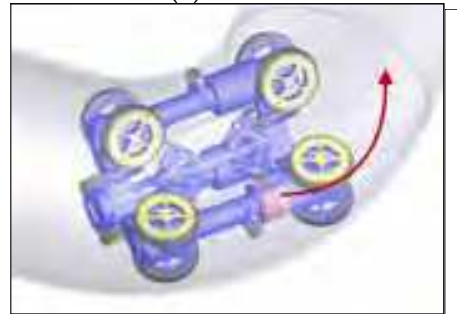

(c)

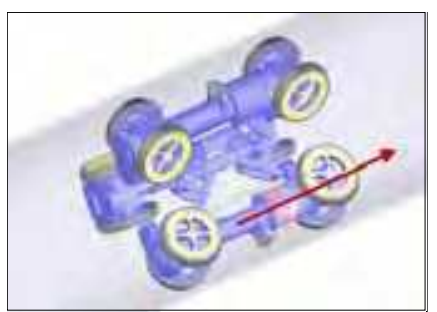

(b)

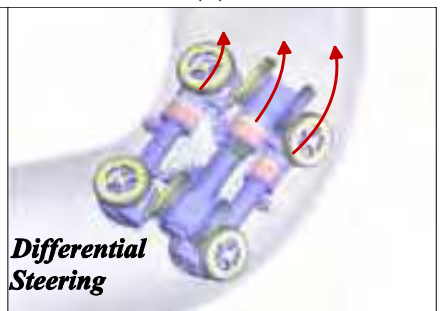

(d)

Figure 33. Feature of MRINSPECT V. (a) Idle State of All Wheels . (b) Single Driving. (c) Single Steering. (d) Differential Steering 
As shown at Fig. 32, overall configuration of MRINSPECT V has a radial shape where a body frame is surrounded by 3 driving units at 120 degrees intervals and the driving units are connected to a link-spring structure for the wall pressing of the wheels. The basic configuration is similar to that of its previous model MRINSPECT IV, although MRINSPECT $V$ features a clutch inside a driving unit, which allows power control between a driving motor and wheels.

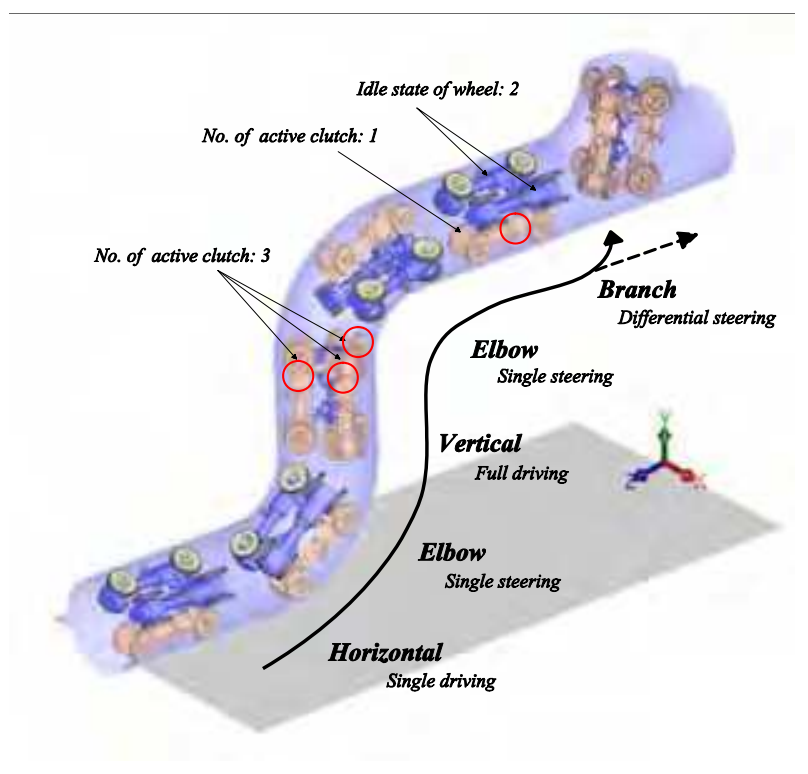

Figure 34. Movement with Selective Driving in Pipelines

As power transmission is cut off by clutch control, wheels can rotate freely without bounding to a driving motor. Application of an idle-state driving mode on wheels enables a user to collect a robot when it is broken down or isolated inside pipelines due to unexpected obstacles, as shown in Fig. 33(a). The proposed robot uses a clutch-based selective driving algorithm to travel effectively inside pipelines. The selective driving algorithm in the study is defined as a way to use both selective driving and differential driving by running a selected driving unit through clutch control while keeping other driving units in an idle state. Since it is not necessary to use all driving units in a horizontal pipe where less pulling capacity is needed, a random single driving unit can be used for driving, as illustrated in Fig. 33(b). Meanwhile, in a curved pipe, the internal shape of pipelines plays a role as a guide and path to keep the direction of a moving object to go forward. Thus, using a differential driving algorithm that runs all driving units like in MRINSPECT IV is unreasonable in this case. Instead using a single driving unit can improve driving efficiency as shown in Fig. 33(c). Meanwhile, a elbow connected to a vertical pipe needs significant pulling capacity, which makes a robot unable to travel only with a single driving unit. Then, all driving units can be operated to obtain necessary pulling capacity and driven in a differential driving algorithm (see Fig. 33(d)). It is same in a vertical pipe since a robot should endure its own weight for driving with full pulling capacity. Likewise, all driving units need to be operated in a branch pipe as the robot is steered using differences of speeds 
of each driving unit. Fig. 34 shows a process that a robot moves forward enduring gravity, which is the most difficult obstacle in driving among pipe elements, in a section from a horizontal, a curved and a vertical pipe to a branch pipe. Each section is illustrated with an appropriate selective driving algorithm as mentioned above. Application of the selective driving algorithm provides flexibility for a robot to travel each type of pipelines by using specific driving units for each situation; in the previous models, all driving units were used regardless of characteristics of pipelines. In particular, using a single driving unit for pipelines where huge pulling capacity is unnecessary can improve power efficiency. In terms of energy efficiency, this is a very useful factor for a free-traveling in-pipe robot that uses batteries as independent power source.

\section{Conclusions}

In this chapter we presented the robotic systems MRINSPECT series for a long-distance inspection of pipelines. The systems show outstanding mobility and several characteristic features, which make it possible to apply the proposed systems in pipelines with complicate geometries regardless of the effect of gravity, its postures, and the direction of moving. Though the algorithms were described based on MRINSPECT series, the ideas can be generalized to the other robots. However, according to our experiences on this work, the mechanism of the in-pipe robot should be adaptable to the characteristic condition of the pipelines and it is the preliminary requirement for the successful movement. The use of a general- purpose robot may not be possible in in-pipe applications. For that means, MRINSPECT series has the possibility of being used in practical applications, although it is still under improvement through testing in the field conditions. In the near future, field tests will be conducted with the system and the system is to be modified according to the results of field evaluation.

\section{Acknowledgments}

This work was partially supported by a grant from the fostering project of the Lab of Excellency of the Ministry of Education and Human Resources Development (MOE), the Ministry of Commerce, Industry and Energy (MOCIE), and the Ministry of Labor (MOLAB) in Korea.

\section{References}

Anthierens, C.; Ciftci, A. \& Betemps, M. (1999), Design of an electro pneumatic micro robot for in-pipe inspection, in Proc. IEEE Int. Symp. Industrial Electronics, vol. 2, pp. 968972.

Anthierens, C.; Libersa, C.; Touaibia, M.; Betemps, M.; Arsicault, M. \& Chaillet, N. (2000), Micro robots dedicated to small diameter canalization exploration, in Proc. IEEE Int. Conf. Intelligent Robots, Systems, vol. 1, pp. 480-485.

Bertetto, A. M. \& Ruggiu, M. (2001), In-pipe inch-worm pneumatic flexible robot, in Proc. IEEE/ASME Int. Conf. Advanced Intelligent Mechatronics, vol. 2, pp. 1226-1231.

Choi, H. R. \& Ryew, S. M. (2002), Robotic system with active steering capability for internal inspection of urban gas pipelines, Mechatronics, vol. 26, no. 1, pp. 105-112. 
Fukuda, T.; Hosokai, H. \& Uemura, M. (1989), Rubber gas actuator driven by hydrogen storage alloy for in-pipe inspection mobile robot with flexible structure, in Proc. IEEE Int. Conf. Robotics, Automation, vol. 3, pp. 1847-1852.

Gamble, B. B. \& Wiesman, R. M. (1996), Tethered Mouse System for Inspection of Gas Distribution Mains, Gas Res. Inst., Doc. GRI-96/0209.

Hayashi, I.; Iwatsuki, N. \& Iwashina, S. (1995), The running characteristics of a screwprinciple microrobot in a small bent pipe, in Proc. Int. Symp. Micro Machines, Human Science, pp. 225-228.

Hayashi, I. \& Iwatsuki, N. (1998), Micro moving robotics, in Proc. IEEE Int. Conf. Intelligent Robots, Systems, pp. 41-50.

Hirose, S.; Ohno, H.; Mitsui, T. \& Suyama, K. (1999), Design of in-pipe inspection vehicles for $\phi 25, \phi 50, \phi 150$ pipes, in Proc. IEEE Int. Conf. Robotics, Automation, pp. 23092314.

Horodinca, M.; Dorftei, I.; Mignon, E. \& Preumont, A. (2002), A simple architecture for inpipe inspection robots, in Proc. Int. Colloq. Mobile, Autonomous Systems, pp. 61-64.

Iwashina, S.; Hayashi, I.; Iwatsuki, N. \& Nakamura, K. (1994), Development of in-pipe operation micro robots, in Proc. Int. Symp. Micro Machines Human Science, pp. 41-45.

Jun, L.; Sun, P.; Lian, L.; Qin, X. \& Gong, Z. (1999), Improvement of characteristics of in-pipe micro robot, in Proc. Int. Symp. Micromechatronics, Human Science, pp. 153-156.

Kawaguchi, Y.; Yoshida, I.; Kurumatani, H.; Kikuta, T. \& Yamada, Y. (1995), Internal pipe inspection robot, in Proc. IEEE Int. Conf. Robotics, Automation, pp. 857-862.

Kolesnik, M. (2002), Visual orientation in the sewer-Adaptation to the environment, in Proc. Int. Conf. Pattern Recognit., pp. 11-15.

Kondoh, Y. \& Yokota, S. (1997), Micro in-pipe mobile machines by making use of an electrorheological fluid, in Proc. IEEE Int. Conf. Intelligent Robots, Systems, vol. 3, pp. 16721677.

Kostin, G. V.; Chernousko, F. L. \& Bolotnik, N. N. (1993), Regular motions of a tubecrawling robot: Simulation and optimization, in Proc. Workshop Robot Motion Control, pp. 45-50.

Landsberger, S. E. \& Martin, B. F. (1992), The design of a pipe crawling robot for control of zebra mussel infestations, in Proc. Mastering the Oceans Through Technology, vol. 2, pp. 819-824.

Menciassi, A.; Park, J. H.; Lee, S.; Gorinil, S.; Dario, P. \& Park, J.-O. (2002), Robotic solutions and mechanisms for a semi-autonomous endoscope, in Proc. IEEE/RSJ Int. Conf. Intelligent Robots, Systems, pp. 1379-1384.

Mhramatsu, M.; Namiki, N.; Koyama, U. \& Suga, Y. (2000), Autonomous mobile robot in pipe for piping operations, in Proc. IEEE/RSJ Int. Conf. Intelligent Robots, Systems, vol. 3, pp. 2366-2171.

Mitsumoto, N.; Tsuruta, K.; Shibata, T. \& Kawahara, N. (2001), Wireless link system for communication and energy transmission of microrobot, in Proc. Int. Symp. Micromechatronics, Human Science, pp. 107-112.

Nagano, S. \& Oka, Y. (1998), Application of in-pipe visual inspection robot to piping internal surface lining, in Proc. 5th Int. Symp. Robotics in Construction, pp. 897-906.

Neubauer, W. (1994), A spider-like robot that climbs vertically in ducts or pipes, in Proc. IEEE/RSJ Int. Conf. Intelligent Robots, Systems, pp. 1178-1185. 
Nickols, F.; Ho, D.; Harrold, S. O.; Bradbeer, R. T. \& Yeung, L. (1997), An ultrasonically controlled robot submarine for pipe inspection, in Proc. 4th Annu. Conf. Mechatronics, Machine Vision in Practice, pp. 142-147.

Nishikawa, H.; Sasaya, T.; Shibata, T. \& Kaneko, T. (1999), In-pipe wireless micro locomotive system, in Proc. Int. Symp. Micromechatronics, Human Science, pp. 141-147.

Ong, J. K.; Kerr, D. \& Bouazza-Marouf, K. (2001), In-pipe multi-robot system: Modular configurable co-operative semi-autonomous robotic units, in Proc. Int. Gas Research Conf., Paper Do07.

Okada T. \& Kanade T. (1987), A three-wheeled self-adjusting vehicle in a pipe, FERRET-1, Int. J. Robot. Res., vol. 6, no. 4, pp. 60-75, 1987.

Okamoto, J.; Adamowski, Jr. J. C.; Tsuzuki, M. S. G.; Buiochi, F. \& Camerini, C. S. (1999), Autonomous system for oil pipelines inspection, Mechatronics, vol. 9, pp. 731-743

Pfeiffer, F.; Robmann, T. \& Loffer, K. (2000), Control of a tube crawling machine, in Proc. Int. Conf. Control of Oscillations and Chaos, vol. 3, pp. 586-591.

Roman, H. T.; Pellegrino, B. A. \& Sigrist, W. R. (1993), Pipe crawling inspection robots: An overview, IEEE Trans. Energy Convers., vol. 8, pp. 576-583, Sept.

Roh, S. G.; Ryew, S. M.; Yang, J. H. \& Choi, H. R. (2001), Actively steerable inpipe inspection robots for underground urban gas pipelines, in Proc. IEEE Int. Conf. Robotics, Automation, pp. 761-766.

Roh, S. G. \& Choi, H. R (2002) Strategy for Navigation Inside Pipelines with Differentialdrive Inpipe Robot, In Proc. IEEE Int. Conf. Robotics, Automation, pp. 2575-2580.

Roh, S. G. \& Choi, H. R. (2005), Differential-Drive In-Pipe Robot for Moving Inside Urban Gas Pipelines, IEEE Trans. Robotics, Vol. 21, No.1, pp.1-17.

Ryew, S. M.; Baik, S. H.; Ryu, S. W.; Jung, K. M.; Roh, S. G. \& Choi, H. R. (2000), Inpipe inspection robot system with active steering mechanism, in Proc. IEEE Int. Conf. Intelligent Robots, Systems, pp. 1652-1657.

Schempf, H. (2002), GRISLEE: Gas Main Repair and Inspection System for Live-Entry Environments, Gas Res. Inst., Doc. GRI-02/0132.

Schempf, H. \& Vradis, G. (2005), Explorer: Long-range untethered real-time live gas main inspection system. presented at Proc. Conf. GTI. [Online]. Available: http://www.rec.ri.cmu.edu/projects/explorer

Scholl, K.-U.; Kepplin, V.; Berns, K. \& Dillmann, R. (2000), Controlling a multijoint robot for autonomous sewer inspection, in Proc. IEEE Int. Conf. Robotics, Automation, vol. 2, pp. 24-28.

Shibata, T.; Sasaya, T. \& Kawahara, N. (1998), Microwave energy supply system for in-pipe micromachine, in Proc. Int. Symp. Micromechatronics, Human Science, pp. 237-242.

Suzumori, K.; Hori, K. \& Miyagawa, T. (1998), A direct-drive pneumatic stepping motor for robots: Designs for pipe-inspection microrobots and for human-care robots, in Proc. IEEE. Int. Conf. Robotics, Automation, vol. 4, pp. 3047-3052.

Suzumori, K.; Miyagawa, T.; Kimura, M. \& Hasegawa, Y. (1999) Micro inspection robot for 1-in pipes, IEEE/ASME Trans. Mechatronics, vol. 4, pp. 286-292, Sep.

Takahashi, M.; Hayashi, I.; Iwatsuki, N.; Suzumori, K. \& Ohki, N. (1994), The development of an in-pipe microrobot applying the motion of an earthworm, in Proc. Int. Symp. Micro Machines, Human Science, pp. 35-40. 
Tsubouchi, T.; Takaki, S.; Kawaguchi, Y. \& Yuta, S. (2000), A straight pipe observation from the inside by laser spot array and a TV camera, in Proc. IEEE/RSJ Int. Conf. Intelligent Robots, Systems, vol. 1, pp. 82-87.

Tsuruta, K.; Sasaya, T.; Shibata, T. \& Kawahara, N. (2000), Control circuit in an in-pipe wireless micro inspection robot, in Proc. Int. Symp. Micromechatronics, Human Science, pp. 59-64. 


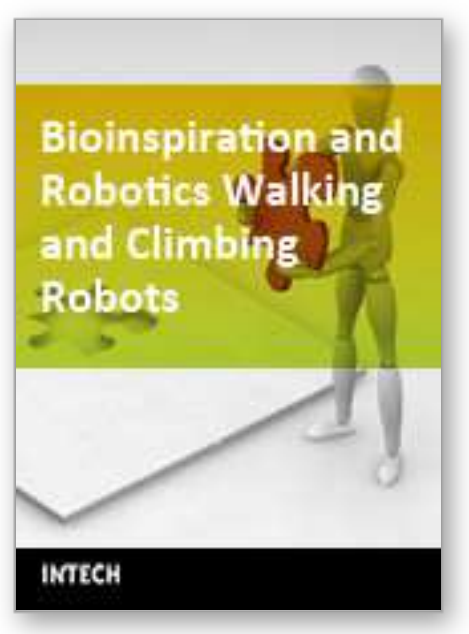

\section{Bioinspiration and Robotics Walking and Climbing Robots \\ Edited by Maki K. Habib}

ISBN 978-3-902613-15-8

Hard cover, 544 pages

Publisher I-Tech Education and Publishing

Published online 01, September, 2007

Published in print edition September, 2007

Nature has always been a source of inspiration and ideas for the robotics community. New solutions and technologies are required and hence this book is coming out to address and deal with the main challenges facing walking and climbing robots, and contributes with innovative solutions, designs, technologies and techniques. This book reports on the state of the art research and development findings and results. The content of the book has been structured into 5 technical research sections with total of 30 chapters written by well recognized researchers worldwide.

\section{How to reference}

In order to correctly reference this scholarly work, feel free to copy and paste the following:

Hyouk Ryeol Choi and Se-gon Roh (2007). In-pipe Robot with Active Steering Capability for Moving Inside of Pipelines, Bioinspiration and Robotics Walking and Climbing Robots, Maki K. Habib (Ed.), ISBN: 978-3902613-15-8, InTech, Available from:

http://www.intechopen.com/books/bioinspiration_and_robotics_walking_and_climbing_robots/inpipe_robot_with_active_steering_capability_for_moving_inside_of_pipelines

\section{INTECH}

open science | open minds

\author{
InTech Europe \\ University Campus STeP Ri \\ Slavka Krautzeka 83/A \\ 51000 Rijeka, Croatia \\ Phone: +385 (51) 770447 \\ Fax: +385 (51) 686166 \\ www.intechopen.com
}

\author{
InTech China \\ Unit 405, Office Block, Hotel Equatorial Shanghai \\ No.65, Yan An Road (West), Shanghai, 200040, China \\ 中国上海市延安西路65号上海国际贵都大饭店办公楼 405 单元 \\ Phone: +86-21-62489820 \\ Fax: +86-21-62489821
}


(C) 2007 The Author(s). Licensee IntechOpen. This chapter is distributed under the terms of the Creative Commons Attribution-NonCommercial-ShareAlike-3.0 License, which permits use, distribution and reproduction for non-commercial purposes, provided the original is properly cited and derivative works building on this content are distributed under the same license. 